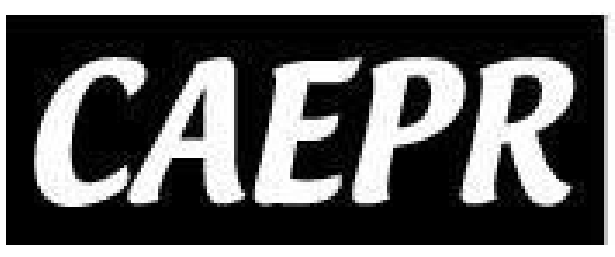

CENTER FOR APPLIED ECONOMICS AND Policy Research

\author{
CAEPR Working
}

Paper

\#2017-003

\title{
Interdependence of Trade Policies in General Equilibrium
}

\author{
Mostafa Beshkar \\ Indiana University
}

Ahmad Lashkaripour
Indiana University

April 5, 2017

This paper can be downloaded without charge from the Social Science Research Network electronic library at https://ssrn.com/abstract $=2947830$

The Center for Applied Economics and Policy Research resides in the Department of Economics at Indiana University Bloomington. CAEPR can be found on the Internet at: http://www.indiana.edu/ caepr. CAEPR can be reached via email at caepr@indiana.edu or via phone at 812-855-4050.

C2017 by Mostafa Beshkar and Ahmad Lashkaripour. All rights reserved. Short sections of text, not to exceed two paragraphs, may be quoted without explicit permission provided that full credit, including ${ }^{\circledR}$ notice, is given to the source. 


\title{
Interdependence of Trade Policies in General Equilibrium
}

\author{
Mostafa Beshkar \\ Indiana University
}

\author{
Ahmad Lashkaripour \\ Indiana University
}

April 5, 2017

\begin{abstract}
We characterize the optimal trade tax/subsidy schedule in generalequilibrium multiple-sector gravity models and find that: (i ) The optimal tariffs are uniform across sectors, despite sectoral variations in trade elasticities, transport costs and demand characteristics; ( ii ) The optimal export subsidy for a sector is increasing in that sector's trade elasticity. Moreover, trade policies are interdependent: ( iii ) Import tariffs across sectors are complementary and (iv ) Import policy is only an imperfect substitute for export policy. These policy interdependencies play an important role in the optimal design of trade agreements and provide a novel perspective on the WTO's ban on export subsidies. Fitting our model to trade data, we show that these policy interdependencies are also quantitatively significant. Finally, ( v ) non-revenue trade barriers (such as import bans) could be optimal in a subset of sectors.
\end{abstract}

\section{Introduction}

The gravity models of international trade, in their various reincarnations, have become the predominant framework to study international economics 
problems. But surprisingly, despite their popularity and outstanding empirical success, the gravity models have rarely been used to study optimal sectoral trade policy. Several authors, including Ossa (2014) and Caliendo and Parro (2014), have circumvented the inherent complexities of analyzing trade policy in multi-sector general equilibrium gravity models by resorting to computational analyses. Beyond these quantitative case studies, the analytics of optimal policy within multi-sector gravity models remain largely unknown.

This paper has two main purposes. First, we fill the above gap in the literature by providing the first analytical characterization of optimal trade policy in an important class of multiple-sector general equilibrium gravity models, including Costinot et al. (2011), Chaney (2008), and Fieler (2011). Given their rich general equilibrium structure, these models provide an appropriate environment for the study of policy interdependence. Our second purpose is to characterize the interdependence of trade policies across sectors. To this end, we characterize the constrained optimal policy when a subset of trade policy instruments are exogenously set at a suboptimal level. This characterization is critical in understanding and predicting the response of governments to incomplete trade agreements that only constrain a subset of policy instruments, or protectionist pressures that may arise in a subset of sectors.

We introduce two major policy interdependence results. First, we find that import tariffs are complementary, in the sense that the optimal import tariff in one sector is increasing in the applied tariff of other sectors. ${ }^{1}$ To obtain a general intuition about this result, note that an (exogenous) increase in the tariff of one sector reduces the relative wage of the foreign country by depressing the relative demand for foreign labor. Given the mobility of labor across sectors, the reduction in the foreign wage implies an improved terms of trade and higher import volumes in all other sectors, which in turn

\footnotetext{
${ }^{1}$ While we find that tariffs across sectors within a country are complementary, Bond et al. (2004) and Ornelas (2005) find that for members of a Free Trade Area, internal and external tariffs are complementary. In particular, they find that as a response to tariff cuts within an FTA, the member countries will voluntarily reduce their tariffs on imports from non-members.
} 
increases the marginal value of tariffs in those sectors.

Our analysis also uncovers an interdependence between import and export policies that is akin to but distinct from the Lerner's Symmetry Theorem. We find that Import policy is only an imperfect substitute for export policy-i.e., the equilibrium obtained by optimal import tariffs may be exactly replicated by a set of export policies; but no set of import tariffs could replicate the equilibrium under the optimal export taxes. Therefore, a government cannot achieve the optimal trading equilibrium using import policies alone.

The finding that import policy is an imperfect substitute for export policy provides a rationale for the WTO's ban on export subsidies. The standard terms-of-trade models, however, are unable to provide an economic rationale for this ban, since under those models a ban on export subsidies does not curtail the negative externality of trade policies. ${ }^{2}$ By contrast, in our general equilibrium framework, export policy is shown to be more potent than import policy as an instrument to manipulate a country's terms of trade. Therefore, a ban on export subsidies, even without any restrictions on import tariffs, could reduce the overall level of protection administered by each country. ${ }^{3}$ To see the novelty of this result, note that in a standard

\footnotetext{
${ }^{2}$ The standard trade policy literature works under assumptions that preclude interdependence of trade policies across sectors. In particular, general equilibrium analysis of trade policy is restricted to two-good models in which there is only one import good and one export good. Under a two-good general equilibrium model, even though a ban on export subsidy will prompt a reduction in the import tariff, the effective level of protection will remain unchanged.

Moreover, the study of trade policy in multiple sectors is conducted within a partial equilibrium setting in which sectors are effectively isolated from each other. In such models, an export subsidy has a positive externality on the foreign country as it improves the foreign country's terms-of-trade and, thus, there is no rationale for limiting export subsidies in bilateral negotiations.

${ }^{3}$ Within a heterogenous-firm model, Bagwell and Lee (2015) show that if import tariffs (as well as transportation costs) are very low, then an export subsidy may benefit a country at the expense of its trading partners. This finding, as they note, provides a partial perspective on the WTO's strict ban on export subsidies. In particular, Bagwell and Lee's finding suggests that a ban on export subsidies is useful only after substantial liberalizations have been reached through previous negotiations. By contrast, our finding suggests that a ban on export subsidies are useful even without any restrictions on import tariffs.
} 
two-sector model, a ban on export subsidy will have no impact on the effective level of protection. ${ }^{4}$

The interdependence of trade policies across sectors provides sharp predictions about the choice of applied tariffs under an incomplete agreement. ${ }^{5}$ In particular, the tariff complementarity result implies that negotiated tariff cuts in a subset of sectors lead to unilateral (i.e., voluntary) tariff cuts in the unbound and loosely bound sectors. ${ }^{6}$ This prediction is in line with the observation that developing countries cut their tariffs unilaterally in sectors where they had high negotiated bindings under the WTO (Martin and Ng 2004). ${ }^{7}$ Moreover, the imperfect substitution between import and export policies implies that a negotiated ban on export subsidies-even without any negotiation on tariff cuts-will reduce unilateral import tariffs and the effective level of protection in a country.

Our result regarding the optimal schedule of trade taxes can be stated as follows. Despite sectoral variations in demand characteristics, trade elasticities, and transport costs, the optimal import tariff is uniform across sectors. The optimal export tax/subsidy, by contrast, varies systematically across sectors. In particular, the optimal export tax in each sector equals the inverse of the foreign country's import demand elasticity, which depends primarily on the sector-wide trade elasticity. ${ }^{8}$

The above finding nests previous general equilibrium characterizations

\footnotetext{
${ }^{4}$ That is because due to Lerner's Symmetry, in a model with one import and one export sector, import and export policies are perfectly substitutable and, thus, no liberalization may be achieved by restricting only one of the instruments.

${ }^{5} \mathrm{An}$ agreement is incomplete if it binds tariffs in only a subset of sectors or if it restricts only some types of policy instruments.

${ }^{6} \mathrm{An}$ unbound sector in a country is one in which no tariff binding is negotiated and, thus, the government is free to choose its tariff unilaterally. A loosely-bound sector is a sector in which a tariff binding is negotiated but the binding is higher than the government's unilateral choice of applied tariff-a phenomenon known as tariff overhang. Beshkar et al. (2015); Beshkar and Bond (2016) provide evidence on the prevalence of sectors with significant tariff overhang.

${ }^{7}$ Baldwin 2010 attributes these unilateral tariff liberalizations to the fragmentation of the production processes. Our theoretical finding that tariffs are complementary suggest that unilateral tariff liberalization in unbound or loosely bound sectors could be the consequence of negotiated tariff cuts in other sectors.

${ }^{8}$ We consider the simultaneous choice of import and export policies to characterize the
} 
of the optimal trade policy (e.g., Opp 2010 and Costinot et al. 2015) as a special case. ${ }^{9}$ In particular, compared to the aforementioned studies, our framework accommodates a general demand structure, non-uniform trade elasticities and transport costs. Moreover, rather than characterizing conditional variations in optimal trade taxes, we derive exact closed-from solutions for the optimal vector of trade taxes. ${ }^{10}$ In a special case of the model where sectors are homogeneous, our optimal trade tax formula converges to the limit-pricing formula characterized by Costinot et al. 2015.

Our findings also shed light on the cause of the optimality of uniform import tariffs and reveal an important caveat about the applicability of this result. Within competitive gravity models, we show that a necessary and sufficient condition for optimality of uniform tariffs is for sector-wide efficiencies to be invariant to trade policy. ${ }^{11}$ As is known from the literature on the non-substitution theorem, under these conditions the relative prices of a country's outputs net of taxes are uniquely determined by the relative sector-wide efficiencies. Therefore, the relative price of the imported goods on the world market are independent of the import tariff structure. On the

optimal trade tax/subsidy schedule. As is known from the work of Bond (1990), the optimality conditions for sectoral trade policies impose a relatively weak restriction on the structure of the optimal trade policy such that there are multiple solutions to the policy optimization problem. To handle multiplicity we invoke a clause in the United States constitution that prohibits export taxes.

${ }^{9}$ Both Opp 2010 and Costinot et al. 2015 adopt Dornbusch et al.'s (1977) version of the Ricardian model to study optimal trade policy. Costinot et al. 2015 go beyond Opp's analysis by including export taxes/subsidies as additional policy instruments that may be used by the government.

${ }^{10}$ Costinot et al. 2015 develop a novel approach that utilizes the additively separable structure of the Dornbusch et al. (1977) model, and characterize variations in the optimal trade tax schedule conditional on foreign wage and a vector of Lagrangian multipliers.

${ }^{11}$ In other words, the optimality of uniform tariffs follows only in the long-run models that assume i) labor is fully mobile and ii) all sectors produce output using labor at a fixed unit labor requirement. We, therefore, argue that the models with the assumptions of full labor mobility and constant labor requirement are more appropriate to study trade agreements rather than unilateral trade policies. That is because unilateral trade policy is a short-run instrument that may be altered very quickly-long before its full effects are realized. Conversely, trade policies that are adopted through multilateral negotiations are more likely to remain in place for a long time due to the obligations of each individual country under trade agreements. 
other hand, uniform tariffs retain the parity between domestic and world relative prices of imports, thereby eliminating one of the distortions created by tariffs. In monopolistically competitive models, in addition to the invariance of sector-wide efficiencies to policy, the optimality of uniform tariffs requires conditions that preclude profit shifting and firm-delocation effects.

Our analysis has novel implications about the optimality of Non-Revenue Trade Barriers (NRTBs) such as import bans and inefficient customs regulations (i.e., red tapes at the border) that discourage imports but do not generate revenues. From the perspective of the standard terms of trade models, the use of NRTBs by governments is hard to understand as they reduce trade without compensating the resulting consumption loss with a better terms of trade. We, however, find that in absence of revenue-generating measures, a country could still improve its welfare by impeding imports in a subset of sectors. This result follows because restricting imports in one sector improves a country's terms of trade in all other sectors by depressing foreign wages. Therefore, if the consumption loss due to import restriction in a sector is sufficiently small, imposing a NRTB in that sector could be optimal. We show that this condition is satisfied in relatively homogenous sectors where imported varieties could be easily substituted with domestic counterparts. Trade data for the United States indicate that this theoretical result bears economic significance. In particular, we find that in absence of tariffs, it is unilaterally optimal for the United States to use NRTBs to restrict imports in the wheat, rice, dairy, and apparel sectors.

Our analytical results greatly simplify the quantitative analysis of trade policy in multi-sector gravity models. As an application, we use factual trade shares and trade elasticities to compute the optimal tax schedule for the United States and China. We compute that the imposition of unilaterally optimal trade taxes by China would raise its real income per capita by 2.46 percentage points. It is also shown that the welfare increase would be 0.20 percentage points lower if export policies were unavailable, which reflects the imperfect substitutability of import and export policies.

To illustrate the role of policy interdependencies, we conduct two coun- 
terfactual analyses that correspond to incomplete trade agreements. First, to highlight the impact of the WTO's ban on export subsidies, we consider an agreement under which export subsidies are banned but governments are allowed to choose their import tariffs unilaterally. We calculate that, starting from a noncooperative equilibrium, the ban will reduce the optimal import tariffs of the United States by about 44 percentage points. We then consider a more complete agreement under which, in addition to a ban on all export subsidies, tariffs are eliminated in half of the traded sectors. For the the United States, we compute that this agreement will lead to an additional 43 percentage point reduction in the optimal tariffs in the unrestricted sectors.

The origin of the optimum trade policy literature dates back to Bickerdike's (1906) "Theory of Incipient Taxes," in which he proposed that a small import tariff or export tax could enhance a country's welfare if the foreign export supply or import demand functions are not infinitely elastic. Kahn (1947) calculated the exact formula for optimal import tariff to be equal to the inverse of the foreign export supply elasticity. This approach came under criticism due to its disregard for general equilibrium effects (Graaff 1949; Horwell and Pearce 1970; Bond 1990). Nevertheless, the subsequent literature adopted Bickerdike's "elasticity approach" to study the variation in sectoral trade policies (e.g., Grossman and Helpman 1995; Broda et al. 2008; Beshkar et al. 2015). Against the backdrop of these developments, our paper sheds new light on the limitations of the partial equilibrium approach that prevails in the trade policy literature.

The theory of piecemeal tariff reform (Hatta 1977; Fukushima 1979; Anderson and Neary 1992, 2007; Ju and Krishna 2000) is another strand of the literature that is related to our work. This literature is primarily concerned with welfareenhancing tariff reforms that are revenue-neutral (or revenue-enhancing) in a small open economy. A general finding of the piecemeal reform literature is that compressing the variation of existing tariffs in developing countries-by reducing the highest tariff rates and increasing the lowest ones-could increase welfare without decreasing revenues. Although we focus on an entirely different problem in this paper, our finding about uni- 
formity of optimal tariff resonates with this literature's recommendation for tariff reforms.

The paper is organized as follows. In Section 2, we lay down the gravity framework that we use throughout the paper. In Section 3, we derive the optimal tax/subsidy schedule and discuss the robustness of our result to changes in the economic setting. We then analyze the interdependence of trade policies across sectors in Section 4 and provide quantitative analyses in Section 6. Section 7 provides concluding remarks including a discussion on the important implications of policy interdependencies for trade negotiations.

\section{The Economic Environment}

The economy consists of two countries: $h$ (Home) and $f$ (Foreign). There are $K$ asymmetric sectors indexed by $k$, where the number of sectors could be arbitrarily large and possibly infinite. On the supply side, the class of models we consider satisfy three primitive assumptions: $(i)$ one factor of production; (ii) linear cost functions; and (iii) perfect or monopolistic competition. We consider labor as the sole factor of production, with $L_{i}$ denoting the labor endowment in country $i$ and $w_{i}$ denoting the labor wage. ${ }^{12}$

The utility of the representative consumer in country $i$ is given by

$$
W_{i}=U_{i}\left(Q_{i, 1}, \ldots, Q_{i, K}\right),
$$

where $Q_{i, k}(i=h, f)$ is the aggregate consumption in sector $k$ and satisfies the following restriction:

R1. Within sectors, the import demand system is CES in that the price index of the

\footnotetext{
${ }^{12}$ The model could accommodate multiple factors of production. All forthcoming propositions carry over to a multi-factor setting where the share of each factor in production is uniform across sectors.
} 
aggregate consumable in sector $k$ is given by

$$
P_{i, k}=\left(\sum_{j=h, f} N_{j, k} \chi_{j i}\left[\tau_{j i, k} w_{j}\right]^{-\theta_{k}}\right)^{-\frac{1}{\theta_{k}}},
$$

and the share of country j's expenditure on country $i$ exports in sector $k$ is given by a gravity equation:

$$
\lambda_{j i, k}=\frac{N_{j, k} \chi_{j i}\left[\tau_{j i, k} w_{j}\right]^{-\theta_{k}}}{\sum_{n=h, f} N_{n, k} \chi_{n i}\left[\tau_{n i, k} w_{n}\right]^{-\theta_{k}}},
$$

where $\theta_{k}$ denotes the trade elasticity, $\tau_{f h, k}$ denotes the iceberg transport cost of exporting form country $j$ to $i$ in sector $k, N_{j, k}$ denotes the measure of firms from country $j$ in sector $k$, and $\chi_{j i}$ is a function of, and only of, structural parameters distinct from transport costs.

The within-sector trade shares and price indexes, described by R1, are satisfied in many well-known trade models with different underlying microfoundations-including the Armington model, Eaton and Kortum (2002), Krugman (1980), and a special case of Melitz (2003) featuring Pareto distributions of firm-level productivity. Importantly, we impose no restrictions on how the trade elasticities vary across sectors. Similarly, we impose no restrictions on transport costs, as they could vary by sector and be bilaterally asymmetric (i.e., $\tau_{f h, k} \neq \tau_{h f, k}$ ). Internal transport costs are assumed to be zero, i.e., $\tau_{h h, k}=\tau_{f f, k}=1$. A notable feature of the above framework is that it flexibly accommodates both intra-sector trade driven by forces of gravity and inter-sector trade driven by comparative advantage $\left(\theta_{k}\right.$ regulates the former, whereas $N_{i, k} \chi_{j i, k}$ governs the latter)

Denoting national income in country $i$ as $Y_{i}$ and given the trade shares, one could calculate sector-specific trade values as $X_{j i, k}=\lambda_{j i, k} Y_{i, k}$, where $Y_{i, k}$ denotes total expenditure on sector with $\sum_{k} Y_{i, k}=Y_{i}$. We further restrict trade to be balanced-i.e., Home's total imports from Foreign equals its total exports. In our framework, equilibrium wages are thus pinned down by the 
balanced trade condition, which is highlighted in the following.

R2. Trade is balanced: $\sum_{k=1}^{K} X_{f h, k}=\sum_{k=1}^{K} X_{h f, k}$.

We also impose that entry is restricted. In particular, the measure of varieties from a given country in sector $k$ (namely, $N_{j, k}$ ) does not respond to the imposition of a trade tax by the Home country in sector $g$ (namely, $t_{g}$ ).

R3. Entry is restricted: $\frac{d N_{i, k}}{d t_{g}}=0$.

Notice that R3 holds trivially in competitive models (e.g., multi-sector Eaton and Kortum (2002) and Armington models) in which $N_{j, k} \equiv 1$. Assumption 3, however, rules out firm-delocation effects and restricts the set of monopolistically competitive models covered by our theory. Finally, we assume that that total income from profits in country $i$ (namely, $\Pi_{i}$ ) is a constant share of total labor Income, $R_{i}=w_{i} L_{i}$ :

R4. Income from profits are a constant share of Labor Income: $\frac{\Pi_{i}}{R_{i}}=\gamma$.

Again, R4 holds trivially for competitive models, in which $\gamma=0$. In a multi-sector Krugman model R4 holds when trade elasticities are uniform across sectors (though sectors could remain asymmetric in other aspects such as income-elasticity). The above restriction also holds in Chaney's (2008) version of the Melitz model where trade and demand elasticities vary across sectors, but aggregate profits are collected by a global fund and redistributed among workers. ${ }^{13}$ As we discuss later, R4 eliminates the profitshifting motives behind trade policy. It implies that total income in country $i$ equals $Y_{i}=(1+\gamma) w_{i} L_{i}$. Country $i$ 's aggregate welfare is then uniquely pinned down by total income, $Y_{i}$, and sector-specific price indexes:

$$
W_{i}=V_{i}\left(Y_{i}, P_{i, 1}, \ldots, P_{i, K}\right) .
$$

\footnotetext{
${ }^{13}$ In addition to the baseline model of Chaney (2008), our theory applies to a general equilibrium variation of the model where all goods are costly to trade and wages are endogenously determined. Regarding R4, Footnote 11 in Chaney (2008) shows that aggregate profits (summed up across countries) are always a constant share, $\pi$, of aggregate global labor revenues. Importantly, $\pi$ depends on only the fundamentals of the global economy and is not affected by trade policy. Chaney (2008) then assumes that profits are collected by a global fund and workers in country $i$ receive $\pi \times w_{i} L_{i}$ of the aggregate profits.
} 
Note that despite restrictions R1-R4, our frameworks retains generality and nest an important class of canonical general equilibrium multi-sector trade models. For example, our framework nests a wide range homothetic and non-homothetic multi-sector gravity models- including Chaney (2008) ${ }^{14}$, Costinot et al. (2011), and Fieler (2011). Moreover, our framework nests Dornbusch, Fischer, and Samuelson's (1977) Ricardian model with homogeneoussectors as a special case.

\subsection{Equilibrium with Trade Tax}

Suppose Home has the discretion to manipulate two distinct policy instruments: (i) sector-specific ad-valorem import tariffs/subsidies $t_{k}$ and (ii) sector-specific ad-valorem export taxes/subsidies $x_{k}$. (Negative values of $t_{k}$ and $x_{k}$ indicate subsidy.) In the presence of these policy instruments, trade shares will become

$$
\lambda_{f h, k}=\frac{N_{f, k} \chi_{f h, k}\left[\tau_{f h, k}\left(1+t_{k}\right) w_{f}\right]^{-\theta_{k}}}{N_{h, k} \chi_{h h, k} w_{h}^{-\theta_{k}}+N_{f, k} \chi_{f h, k}\left[\tau_{f h, k}\left(1+t_{k}\right) w_{f}\right]^{-\theta_{k}}},
$$

and

$$
\lambda_{h f, k}=\frac{N_{h, k} \chi_{h f, k}\left[\tau_{h f, k}\left(1+x_{k}\right) w_{h}\right]^{-\theta_{k}}}{N_{h, k} \chi_{h f, k}\left[\tau_{h f, k}\left(1+x_{k}\right) w_{h}\right]^{-\theta_{k}}+N_{f, k} \chi_{f f, k} w_{f}^{-\theta_{k}}} .
$$

Sector-specific f.o.b. trade values will be given by $X_{f h, k}=\frac{\lambda_{f h, k} Y_{h, k}}{1+t_{k}}$ and $X_{h f, k}=$ $\lambda_{h f, k} Y_{f, k}$. Home's income $\left(Y_{h}\right)$ equals the sum of labor and profit income, $(1+\gamma) w_{h} L_{h}$, plus the tax revenue collected across all sectors:

$$
Y_{h}=(1+\gamma) w_{h} L_{h}+\sum_{k=1}^{K} t_{k} X_{f h, k}+\sum_{k=1}^{K} \frac{x_{k}}{1+x_{k}} X_{h f, k}
$$

where $R_{f h} \equiv \sum_{k=1}^{K} t_{k} X_{f h, k}$ and $R_{h f}^{x} \equiv \sum_{k=1}^{K} \frac{x_{k}}{1+x_{k}} X_{h f, k}$ denote tariff and export tax revenue respectively. Foreign's total income, $Y_{f}$, however, remains equal

\footnotetext{
${ }^{14}$ Our framework covers both the baseline Chaney (2008) model, and a variation of the model where all goods are costly to trade and wages are endogenously determined.
} 
to total labor income: $Y_{f}=(1+\gamma) w_{f} L_{f} \cdot{ }^{15}$ As before, wages are pinned down by the balanced trade condition: $\sum_{k=1}^{K} X_{f h, k}=\sum_{k=1}^{K} X_{h f, k}$.

In the above environment, Home's optimum tax schedule $\left\{t_{1}^{*}, \ldots, t_{K}^{*} ; x_{1}^{*}, \ldots, x_{K}^{*}\right\}$ maximizes its national welfare subject to balanced trade:

$$
\begin{aligned}
\left\{t_{1}^{*}, \ldots, t_{K}^{*} ; x_{1}^{*}, \ldots, x_{K}^{*}\right\}= & \arg \max V_{i}\left(Y_{h}, P_{h, 1}, \ldots, P_{h, K}\right) \\
\text { s.t. } & \sum_{k=1}^{K} X_{f h, k}=\sum_{k=1}^{K} X_{h f, k} .
\end{aligned}
$$

The above framework accounts for three general equilibrium margins. First, it accounts for the income effect that is not present in partial equilibrium models. The second margin is the "cross-elasticity" effects that are typically eliminated with the adoption of Cobb-Douglas or quasilinear preferences. ${ }^{16}$ The third margin is the "cross-price" effects that are usually precluded by adopting a framework in which tariffs have no impact on factor rewards. ${ }^{17}$ Our framework, by contrast, accounts for all of these general equilibrium margins. Specifically, tariffs imposed in one particular sector can effect the entire vector of sectoral demands and prices.

\section{Optimal Trade Policy Schedule}

In this section, we solve analytically for the optimal trade policy schedule of the Home country. Solving for the optimal tax schedule in the present multisector general equilibrium framework is plagued by the curse of dimensionality. In this environment, countries buy and sell many goods whose prices depend on the entire vector of net imports through their effects on wages. Hence, solving for the optimal tax vector involves characterizing the best

\footnotetext{
${ }^{15}$ Note that given the above equation we can write total income as a function of wage, taxes, and import shares $Y_{h}=\frac{w_{h} L_{h}+w_{f} L_{f} \sum_{k=1}^{K} \frac{x_{k}}{1+x_{k}} \lambda_{h f, k} \alpha_{f, k}}{1-\sum_{k=1}^{K} \frac{t_{k}}{1+t_{k}} \alpha_{k, h} \lambda_{f h, k}}$.

${ }^{16}$ Quasilinear preferences entail no cross-elasticity among nonlinear goods.

${ }^{17}$ Wages are unaffected by tariffs if it is assumed that all countries produce a positive amount of the linear good at a fixed unit labor requirement. This assumption ensures that tariffs in one sector do not affect the cost of production and prices in other sectors.
} 
policy response in sector $k$ as a function of the policy vectors in all other sectors. Even then, there remains the task of verifying wether the best response functions intersect at a unique global optimum. As noted earlier, the existing literature typically avoids these complications by restricting attention to partial equilibrium environments or two-good (i.e., one sector) economies.

Our approach to solving Problem 1 involves three steps. First, we solve for the vector of optimal import tariffs conditional on zero export tax. The solution to the first step turns out to be a uniform vector of tariffs. In the second step, we prove the uniformity property holds under an arbitrary vector of export taxes. Finally, knowing that the vector of optimal tariffs is uniform, we solve for the optimal trade tax schedule, which consists of a vector of non-uniform export taxes/subsidies and a uniform vector of import tariffs. The following, describes our approach in full detail.

\subsection{Optimal Import Tariffs}

The first stage of our analysis solves a restricted version of Problem 1. Specifically, we characterize the vector of optimal tariffs when export taxes are externally assigned. Before describing our strategy, one should bear in mind that our analysis covers an environment that features a discrete number of sectors that are either differentiated or homogeneous. Characterizing the optimal tariff across differentiated sectors is a smooth problem. Homogeneous sectors are however subject to knife edge equilibria, and solving for the optimal tariff across these sectors involves a non-smooth welfare maximization problem. One approach to smoothing the problem in such cases is to assume a continuum of (measure zero) sectors. ${ }^{18}$ Here we employ an alternative strategy. We characterize the optimal policy vector for a countable number of sectors with an arbitrary vector of $\theta_{k}$ 's. Then, to determine the optimal policy for homogeneous sectors, we calculate the solution in the

\footnotetext{
${ }^{18}$ This approach was initially developed by Dornbusch et al. (1977), and has been employed by Opp (2010) and Costinot et al. (2015) in the context of optimal trade policy.
} 
limit where $\theta_{k} \rightarrow \infty$.

Starting with zero export tax, we characterize the vector of optimal tariffs in three basic steps. First, we observe that casting the problem in terms of f.o.b. trade values rather than trade shares (which is the traditional approach) greatly simplifies the problem. Second, for a given sector, we show that any solution to the first order condition (FOC) consists of vectors that include only aggregate variables. The second step, therefore, establishes uniformity. Given the uniform structure, solving for the vector of optimal tariffs becomes rather straightforward. In particular we show that $(i)$ a unique vector of uniform tariffs solves the FOC, and that (ii) this unique vector constitutes a global maximum. Our findings are summarized in the following proposition.

Proposition 1. For an arbitrary set of export taxes/subsidies, the optimal import tariffs is unique and uniform across all sectors. Moreover, for zero export taxes/subsidies, the optimal import tariff is equal to Home's average export elasticity:

$$
t_{1}^{*}=\ldots=t_{K}^{*}=\frac{1}{\epsilon_{h f}},
$$

where where $\epsilon_{h f} \equiv \partial \ln \lambda_{h f} / \partial \ln w$ represents the elasticity of Foreign's aggregate demand for Homes's exports.

Proposition 1 simply states that the optimal import tax reflects Home's collective monopoly power across all sectors. Noting that $\lambda_{h f}=\sum_{k=1}^{K} \alpha_{f, k} \lambda_{h f, k}$ (where $\alpha_{f, k} \equiv Y_{f, k} / Y_{f}$ ), Proposition 1 implies the following equation for optimal tariffs:

$$
\bar{t}^{*}=\frac{1}{\tilde{\theta}_{h f} \lambda_{f f}+\sum_{k=1}^{K}\left(\frac{X_{h f, k}}{X_{h f}}-\alpha_{f, k}\right) \frac{\partial \ln \alpha_{f, k}}{\partial \ln w}},
$$

where $\tilde{\theta}_{h f} \equiv \sum \alpha_{f, k} \frac{\lambda_{f h, k}}{\lambda_{f h}} \frac{\lambda_{f f, k}}{\lambda_{f f}} \theta_{k}$ could be viewed as the weighted average elasticity of Foreign demand for Homes's exports. The first term in Equation 3, $\tilde{\theta}_{h f} \lambda_{f f}$, corresponds to "cross-price" effects (i.e., $\partial w_{f} / \partial t_{k}$ ), which reflect the ability of import policy to manipulate the vector of Foreign prices through the economy-wide wage. Previously, Gros (1987) and Alvarez and Lucas 
(2007) have characterized the role of "cross-price" effects, but only in the context of a single sector economy. Notably, in the presence of differentiated sectors, these effects retain quantitative importance even when Home is a small open economy (i.e., $\lambda_{f f} \approx 1$ ).

The second term in Equation 3, $\sum_{k=1}^{K}\left(\frac{X_{h f, k}}{X_{h f}}-\alpha_{f, k}\right) \frac{\partial \ln \alpha_{f, k}}{\partial \ln w}$, corresponds to the "cross-elasticity" effects highlighted in Graaff (1949). Broadly speaking, the "cross-elasticity" effects should lower the optimal tariff when preferences are homothetic-an issue we will elaborate on later in Section 3.3 using the example of CES preferences. The cross-elasticity effects, however, could be more nuanced under non-homothetic preferences. For example, suppose Home has a comparative advantage in income-elastic sectors: $\frac{\partial \ln \alpha_{f, k}}{\partial \ln w}>0 \Longleftrightarrow \frac{X_{h f, k}}{X_{h f}}>\alpha_{f, k}$. The cross-elasticity effects would encourage Home to charge lower tariffs. The intuition is straightforward: tariffs lower Foreign's income and shift expenditure away from income-elastic goods. If Home exports predominantly in income-elastic sectors, it would set lower tariffs to somewhat prevent these consumption-shifting effects.

The contribution of Proposition 1 to existing theories is two-fold. First, it extends Costinot et al. (2015) and Opp's (2010) results to a setting with asymmetric sectors and a more general demand structure. Second, it derives a closed-form solution for the optimal tariff, which greatly facilitates trade policy analysis in quantitive trade models. Later, in Section 6, we will explore the quantitative dimensions of our theory.

There is simple intuition behind the uniformity of optimal tariffs. In our long-run gravity framework, non-uniform tariffs have a uniform effect on Foreign prices (through the economy-wide wage), but distort domestic prices. The optimal import policy, therefore, is a uniform tariff that causes minimal distortion to domestic consumption. Importantly, the uniformity result in monopolistic competition models hinges on restrictions R3 and R4. Relaxing R3 activates firm-delocation effects. Relaxing R4 activates the profit-shifting motives behind import policy. Activating either channel would lead to non-uniform optimal tariffs. In competitive models, however, uniformity is driven solely by the primitive linear cost assumption. 
Relaxing this assumption, which is only sensible in the short-run, would also lead to non-uniform tariffs. Therefore, one could argue that in competitive models, long-run tariffs are uniform, whereas short-run tariffs are not. Altogether, while the uniformity result may be unstable by itself, Proposition 1 suggests that accounting for previously-overlook general equilibrium margins would always dampen sectoral variations in the optimal import tax.

Proposition 1 characterizes the optimal tariffs when Foreign imposes zero tax on its exports/imports. Optimal tariffs nonetheless remain uniform even when the Foreign country imposes a non-uniform tariff on Home's exports. In the special (an more relevant) case where Foreign imposes a uniform tariff $t_{h f}$ on Homes's export, Home's optimal tariff will be given by

$$
\bar{t}^{*}=\frac{1-\rho_{f}}{\epsilon_{f h}},
$$

where $\rho_{f} \equiv t_{f h} X_{f h} / Y_{f}$ denotes the share of tariff revenues in Foreign's income. Given that an increase in Foreign tariff, $t_{f h}$, typically increases $\epsilon_{f h}$ and $\rho_{f}$, the above formula indicates that tariffs are strategic substitutes.

\subsection{The Optimal Trade Tax Schedule}

We now turn to characterizing the full vector of optimal trade taxes. To this end, we analytically solve Problem 1 without imposing restrictions on either import or export taxes. While the Lerner symmetry establishes equivalence between uniform export and import taxes; non-uniform export and import taxes remain distinct. Export taxes can be used to target Home's sectorspecific monopoly power without directly distorting domestic prices. Import tariffs, by contrast, distort local prices and can only manipulate Home's aggregate monopoly power through the economy-wide relative wage $\left(w_{h} / w_{f}\right)$.

Given the above distinctions, characterizing the optimal vector of export taxes requires a distinct approach. Following Proposition 1, we simply need to solve for the optimal vector of export taxes conditional on uniform 
tariffs (which are set to zero initially: $\mathbf{t}=\mathbf{0}$ ). In the general case, we can show that the vector of optimal export taxes, $\mathbf{x}^{*}$, should be non-uniform. The lack of uniformity, however, makes the task of finding a closed-form solution more challenging. We can nonetheless produce a closed-form solution for the case where cross-elasticity effects are absent (i.e., constant $\alpha_{j, k}$ 's). Our approach involves the construction of a simple one-to-one transformation, $\mathbf{x} \rightarrow \hat{\mathbf{x}}$, where $\mathbf{x}$ denotes the vector of export taxes. Writing the first order conditions in terms of $\hat{\mathbf{x}}$ greatly simplifies the problems as it entails a unique solution with uniform elements. The optimal export tax, $\mathbf{x}^{*}$ is then attained by performing a simple re-transformation. Finally, applying the Lerner symmetry we can characterize the optimal tax schedule, $\left\{\mathbf{t}^{*}, \mathbf{x}^{*}\right\}$, up to any given uniform tariff. These findings are summarized in the following Proposition:

Proposition 2. The optimal trade tax/subsidy schedule consists of a uniform tariff and sector-specific (non-uniform) export taxes/subsidies. Moreover, if $\alpha_{i, k}$ 's are constant, the optimal tax schedule is uniquely determined up to a uniform tariff $t^{*}$ according to the following equation:

$$
\left(1+x_{k}^{*}\right)\left(1+t^{*}\right)=\frac{1}{\epsilon_{h f, k}}, \quad k=1, . ., K .
$$

where $\epsilon_{h f, k} \equiv \frac{\partial \ln \lambda_{h f . k}}{\partial \ln 1+x_{k}}=\theta_{k} \lambda_{f f, k}$ represents the elasticity of Foreign's demand for Homes's exports in sector $k$.

The above proposition simply states that the optimal export tax reflects Home collective monopoly power in a given sector. However, due to the Lerner symmetry the optimal policy is indeterminate, but unique up to a uniform tariff-i.e., pining down the uniform tariff uniquely determines the vector of optimal export taxes. To elaborate on the issue of multiplicity, notice that Home could achieve the optimal level of protection by either pairing a high import tariff with export subsidies or by pairing a low import tariff with high export taxes. Figure 1 illustrates the indeterminacy of the optimal tax for a one sector economy under various values of $\theta$. 
Figure 1: The optimal trade tax schedules for various values of $\theta$.

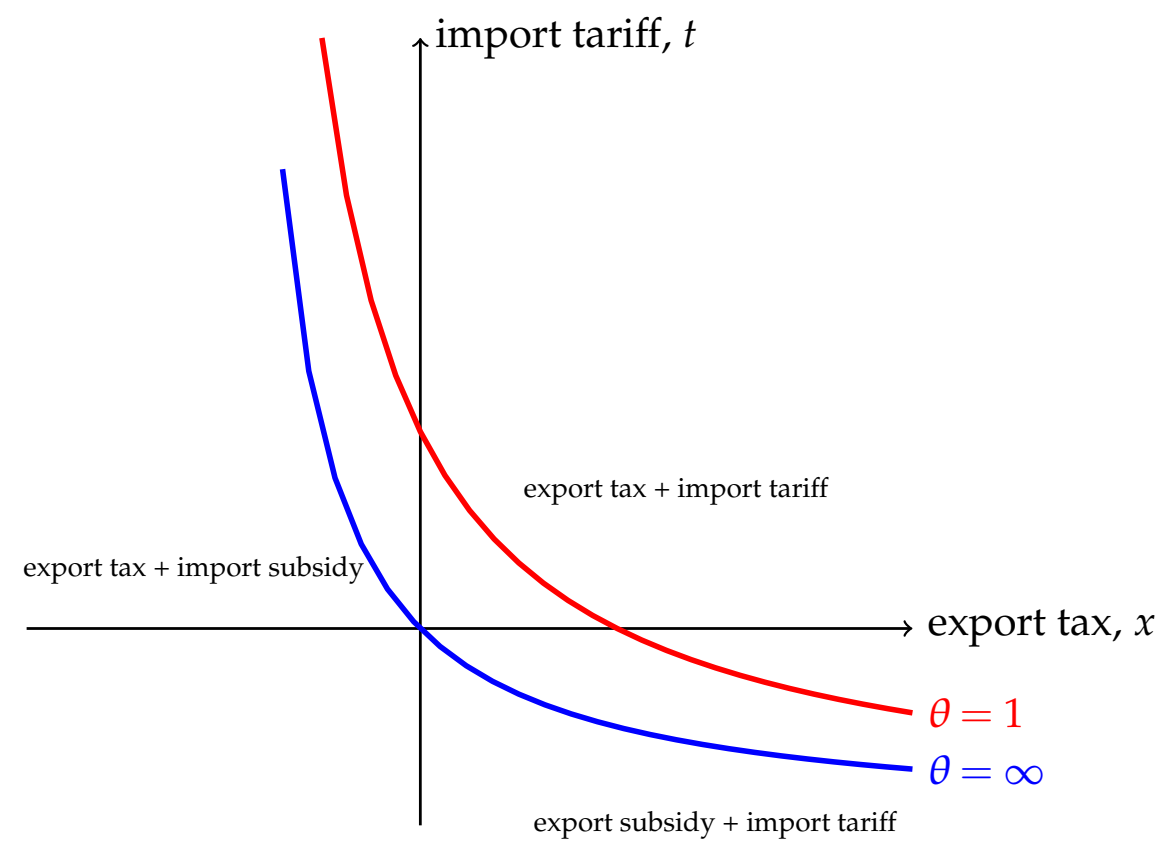

Note: The figure is plotted based on the assumption that Home is small compared to the Foreign (i.e. rest of the world): $\lambda_{f f} \approx 1$. 
To put our contribution in perspective, note that Proposition 2 generalizes Costinot et al. (2015) in that it characterizes the optimal trade tax across sectors that feature non-uniform trade elasticities and transport costs. In addition, it provides an exact solution for the optimal trade tax vector, whereas Costinot et al. (2015) characterize conditional variations in the optimal trade tax for a given vector of wage and Lagrangian multipliers. Costinot et al. (2015), however, characterize these variations under a CES utility aggregator, whereas our closed-form solution applies only to the case where preferences are Cobb-Douglas across product/sectors.

Beyond these distinctions, the optimal trade tax formula described by Proposition 2 nests the limit-pricing scheme outlined in Costinot et al. (2015) as a special case-our formula converges to the limit-pricing formula when $\theta_{k} \rightarrow \infty$. Furthermore, note that our closed-from solution (despite its limitation) characterizes the optimal policy in a long list of canonical multi-sector gravity models-including a general equilibrium version of Chaney (2008) and Costinot et al. (2011). We will demonstrate in Section 6, that the exact closed-from solution offered by Proposition 2 greatly simplifies the quantitative analysis of trade policy in these so-called gravity models.

\subsection{Two Special Cases}

As stated earlier, our framework nests a wide range of multi-sector gravity models-including those with homothetic preferences (e.g., Chor 2010; Costinot et al. 2011) and non-homothetic preferences (e.g., Fieler 2011; Caron et al. 2014). Additionally, our framework accommodates an arbitrarily large (possibly infinite) number of sectors and nests the Dornbusch et al. (1977) model as a special case where sectors are homogeneous (i.e., $\theta_{k} \rightarrow \infty$ for all $k$ ). Below, we build on Propositions 1 and 2 to explore the optimal policy in these special cases independently. 


\section{Multi-Sector Gravity Model: Many Differentiated Sectors}

As a starting point we consider a basic multi-sector gravity model (in style of Chaney (2008) and Costinot et al. (2011)) where preferences across sectors are described by a Cobb-Douglass utility function:

$$
U_{i}\left(Q_{i, 1}, \ldots, Q_{i, K}\right)=\Pi_{k} Q_{i, k}^{\alpha_{i, k}} .
$$

This special case is essentially a general equilibrium framework without cross-substitution effects. Hence, provided that $\frac{\partial \ln \alpha_{f, k}}{\partial \ln w}=0$, the optimal tariff (conditional on no export policy) will be uniform and described by:

$$
\bar{t}^{*}=\frac{1}{\tilde{\theta}_{h f} \lambda_{f f}} .
$$

For a single sector economy the above formula reduces to $t^{*}=\frac{1}{\theta \lambda_{f f}^{*}}$, which is analogous to the formula derived in Gros (1987). The full vector of optimal trade taxes, meanwhile, will consist of a uniform tariff, $\bar{t}^{*}$, and sectorspecific export taxes/subsidies that are characterized by:

$$
\left(1+\bar{t}^{*}\right)\left(1+x_{k}^{*}\right)=\frac{1}{\theta_{k} \lambda_{f f, k}}
$$

Altogether, the above equation identifies three factors that shape the optimal trade policy vector. First, the sector-wide transport costs- the optimal export subsidy is higher in less tradable, high transport cost sectors. The second factor is comparative advantage, with the optimal export subsidy being higher in comparative advantage sectors that display lower $\lambda_{f f, k}$ 's. Last and most importantly, the optimal export subsidy varies systematically with the trade elasticity. In particular, the optimal export subsidy is higher in less-differentiated, high- $\theta$, sectors. Fitting the above model to factual trade elasticities and trade shares in Section 6, we find that sectoral variations in the optimal export subsidy are near-exclusively driven by variations in the trade elasticity. 
CES Utility Aggregator. Now, we consider a gravity model that features a less-restrictive CES utility aggregator across sectors. By doing so, we demonstrate how the widely-used Cobb-Douglass utility aggregator is not fully innocuous as far calculating the optimal tariffs go. To be specific, consider the following utility function across sectors:

$$
U_{i}\left(Q_{i, 1}, \ldots, Q_{i, K}\right)=\left[\sum_{k=1}^{K} Q_{i, k}^{\frac{\sigma-1}{\sigma}}\right]^{\frac{\sigma}{\sigma-1}} .
$$

The above utility implies that $\lambda_{h f}=\sum \alpha_{f, k} \lambda_{f h, k}$ where $\alpha_{f, k} \equiv\left(P_{h . k} / P_{h}\right)^{1-\sigma}$-with $P_{h}=\left(\sum_{g} P_{h, g}^{1-\sigma}\right)^{1 /(1-\sigma)}$ denoting Home's aggregate price index. The CES case, therefore, accommodates cross-substitution effects. Following Proposition 1, the optimal import tariff (conditional on no export policy) remains uniform, but is described by the following equation:

$$
\bar{t}^{*}=\frac{1}{\tilde{\theta}_{h f} \lambda_{f f}+(\sigma-1) \sum_{k} \frac{\alpha_{f, k} \lambda_{h f, k}}{\lambda_{h f}}\left[\lambda_{h f, k}-\lambda_{h f}\right]}>\frac{1}{\tilde{\theta}_{h f} \lambda_{f f}},
$$

where the inequality follows from the fact that $\sum_{k} \alpha_{f, k} \lambda_{h f, k}\left[\lambda_{h f, k}-\lambda_{h f}\right]>$ $\sum_{k} \alpha_{f, k}\left[\lambda_{h f, k}-\lambda_{h f}\right]=0$. Put simply, the above inequality states that overlooking cross-substitution effects (with Cobb-Douglas preferences) could overstate the optimal tariff, especially if the factual elasticity of substitution across sectors, $\sigma$, is relatively high.

\section{Dornbusch et al. (1977): Many Homogeneous Sectors}

A special case of our framework is a model in which all sectors are homogeneous (i.e., $\theta_{k} \rightarrow \infty$ ). This special case is analogous to Ricardian model of Dornbusch et al. (1977), which has been previously analyzed in Opp (2010) and Costinot et al. (2015). The presence of homogeneous sectors gives rise to knife-edge trade equilibria-where a small shock to the economy could transform an import sector into an export sector. A common strategy to smooth these knife-edge effects involves assuming a continuum of sectors 
à la Dornbusch et al. (1977). Our framework, however, allows for an alternative smoothing strategy. We retain the discrete structure of the economy, and instead formulate the optimal trade tax problem as the limiting case of the smooth problem characterized by Proposition 2 . Hence, in view of Proposition 2, the optimal trade tax vector is simply given by $\left(1+\bar{t}^{*}\right)\left(1+x_{k}^{*}\right)=1+\lim _{\theta_{k} \rightarrow \infty} 1 / \theta_{k} \lambda_{f f, k}$.

Normalizing the import tariff to zero it follows immediately that in import sectors, where $\lambda_{f f, k} \approx 1$, the export tax is obviously zero. In export sectors, meanwhile, for a sufficiently large $\theta_{k}$ the optimal export tax formula may be written as (see Appendix D)

$$
\left(1+\bar{t}^{*}\right)\left(1+x_{k}^{*}\right)=\frac{T_{h, k}}{T_{f, k}} \tau_{h f, k} w\left[1-\frac{1}{\theta_{k}} \ln \left(\frac{T_{h, k}}{T_{f, k}} \tau_{h f, k} w-1\right) \theta_{k}\right],
$$

where $T$ denotes actual productivity-i.e., $\lambda_{j i, k}=\frac{\left[\tau_{j i, k} w_{j} / T_{j, k}\right]^{-\theta_{k}}}{\sum_{n=h, f}\left[\tau_{n i, k} w_{n} / T_{n, k}\right]^{-\theta_{k}}}$. Normalizing the uniform import tariff component to zero, we will have $\lim _{\theta_{k} \rightarrow \infty} x_{k}^{*}=$ $\frac{T_{h, k}}{T_{f, k}} \tau_{h f, k} w-1$. Altogether, the above equation provides a closed-form characterization of the limit-pricing scheme highlighted in Costinot et al. (2015). Intuitively, the optimality of a limit-pricing tax reflects the Home government's aversion to comparative advantage reversal. Furthermore, the limitpricing tax entails that the optimal export tax increases with Home's comparative advantage in a given sector. Moving away from this limiting case, the role of comparative advantage on optimal policy greatly diminishes. Overall, comparing the two cases covered above, one could argue that across homogeneous sectors/products the optimal policy vector is regulated by comparative advantages, whereas as across differentiated sectors/product optimal policy is regulated by sector-wide trade elasticities. 


\section{Interdependence of Policies}

When sectors are interrelated through various general equilibrium margins, trade policies become interdependent. The optimal tax in one sector depends on the taxes and subsidies applied in other sectors. The existing literature, however, is mostly silent about trade policy interdependencies for two main reasons. First, the focus of the existing literature is on "optimal" policy rather than the tradeoffs that policymakers face outside the optimum. Second, as noted earlier, trade policy analysis across multiple sectors is usually conducted in partial equilibrium frameworks that precludes interrelations across sectors. Below, we take a first stab at filling this gap. We show that in addition to being prevalent, policy interdependencies are systematic.

First, we characterize a systematic pattern of interdependence between sector-wide import tariffs. To this end, we analyze the effect of a tariff liberalization in a subset of sectors (namely, $R$ ) on optimal tariffs in the remaining non-liberalized sectors. Surprisingly, we find that optimal tariffs in non-liberalized sectors remain uniform. More importantly, the optimal tariffs (post partial liberalization) are lower than the unrestricted optimal tariff, $\bar{t}^{*}=1 / \epsilon_{h f}$. To be more specific, let $\dot{t}^{*}$ denote the optimal tariff in nonliberalized sectors; we show that

$$
t_{k}^{*}=\grave{t}^{*}=\frac{1}{\epsilon_{h f}+\sum_{g \in R} \frac{X_{f h, g}}{X_{f h}}\left[1+\omega_{g}\right]}<\bar{t}^{*}=\frac{1}{\epsilon_{h f}}, \quad k \notin R,
$$

where $\omega_{k} \equiv-\partial \ln X_{f h, k} / \partial \ln w>0$. Simply put, The above result states that tariffs are complementary across sectors. Eliminating tariffs in a subset of sectors encourages governments to unilaterally lower tariffs in the nonliberalized sectors. To gain intuition, note that two force contribute to these complementarity effects. First, lowering tariffs in non-liberalized sectors is attractive because it decreases the tariff-induced price distortions. Second, partial liberalization both decreases national income (through tariff revenue cuts) and increases the Foreign wage. Both adjustments decrease the f.o.b. 
value of trade in non-liberalized sectors and the marginal revenue raised from tariff imposition. We summarize these arguments in the following proposition.

Proposition 3. Import tariffs are complementary across sectors: liberalizing tariffs in a subset of sectors lowers the optimal tariff in non-liberalized sectors.

The finding that tariff liberalization in a subset of sectors encourages lower tariffs in non-liberalized sectors is both novel and fundamental to the design of trade agreements-in Section 6, we examine the empirical relevance of these policy interdependencies. Going one step further, we can characterize the optimal import tariff in sector $k$ as a function of the vector of applied tariffs in other sectors. In particular, the FOC corresponding to sector $k^{\prime}$ s tariff, implies the following best response formula:

$$
t_{k}^{*}\left(t_{1}, \ldots, t_{K}\right)=\frac{1+\sum_{g \neq k} t_{g} \frac{X_{f h, g}}{X_{f h}}\left[1+\omega_{g}\right]}{\epsilon_{h f}+\sum_{g \neq k} \frac{X_{f h, g}}{X_{f h}}\left[1+\omega_{g}\right]} .
$$

The above formula also points the complementarity of optimal tariffs: the optimal tariff in sector $k$ increases with the weighted average tariff imposed on the remaining $K-1$ sectors.

Our second finding sheds new light on the interdependence between export and import policies. In view of the Lerner symmetry, it is widely believed that import and export taxes are perfect substitutes. Propositions 1 and 2, however, challenge this belief. Proposition 1 states that the optimal tariff is uniform, whereas Proposition 2 states that the optimal export tax is non-uniform. Hence, applying the Lerner symmetry, the welfare effects of the optimal tariff can be exactly replicated with a uniform export tax, whereas the outcome attained under the optimal export policy is unattainable with any import policy alternative. That is to say, import policy is at most a weak substitute for export policy - a result highlighted in the following proposition.

Proposition 4. Import tariffs are imperfect substitute for export taxes, i.e. gov- 
ernments could achieve higher levels of welfare through export policy than import policy alone.

To offer perspective, note that the above result applies to a wide range of canonical long-run competitive trade models. In this class of models, the sole purpose for either export or import policy is manipulating Home's collective export market power. Whereas import tariffs can only manipulate the economy-wide market power through "cross-price" effects, export taxes can target the sector-wide market power directly. Export taxes therefore offer Home more flexibility in manipulating its terms of trade. Also, notice that while it is well-understood the equivalence between import and export policies may not hold in certain environments, Proposition 4 sets forward a much stronger claim. That is, export policy systematically dominates import policy in wide class of trade models.

Finally, Proposition 4 sheds new light on the WTO's strong restrictions on export subsidies. These restriction are not easy to reconcile with the widespread view that import and export policies are perfect substitutes. Additionally, from the perspective of the classical partial equilibrium theories, export subsidies deteriorate the imposing country's terms of trade. Therefore, if anything there should be an undersupply of export subsidies in the global economy. Either way, based on these theories, restricting export policy alone is ineffective. Proposition 4 , however, states that in a general equilibrium framework export policy is a more flexible tool for terms of trade manipulation. Restricting export policy alone can therefore increase joint efficiency in the global economy.

\section{Non-Revenue Trade Barriers}

Now we consider the case where Home can impose non-revenue trade barriers (NRTB, hereafter) - that is, barriers that restrict trade without generating revenue. In a one-sector or partial-equilibrium economy, optimal NRTBs are "zero" as trade barriers are justified only when they generate 
revenue. We, however, show that in a multi-sector general equilibrium framework, eliminating tariff revenues does not eliminate the incentive to restrict trade in select sectors. To demonstrate this, note that the optimal NRTBs are chosen to solve the following problem:

$$
\begin{aligned}
\left\{\hat{t}_{1}^{*}, \ldots, \hat{t}_{K}^{*}\right\}=\arg \max \frac{w_{h}}{P_{h}} \\
\text { s.t. } \sum_{k=1}^{K} X_{f h, k}=\sum_{k=1}^{K} X_{h f, k} .
\end{aligned}
$$

In Appendix C, we formally establish that, unlike revenue tariffs, optimal NRTBs cannot be both positive and uniform. We further characterize the optimal vector of NRTBs. In particular, defining $\epsilon_{j i, k} \equiv\left|\frac{\partial \ln \lambda_{j i, k}}{\partial \ln w}\right|$ and $\epsilon_{j i} \equiv$ $\left|\frac{\partial \ln \lambda_{j i}}{\partial \ln w}\right|$, the optimal non-revenue trade barriers would be described by

$$
\hat{t}_{k}^{*}= \begin{cases}0 & \text { if } \epsilon_{f h, k} \leq \epsilon_{h f}+\epsilon_{f h}, \\ \frac{1+\epsilon_{f h, k}}{1+\epsilon_{f h}+\epsilon_{f h}}\left(1+\bar{t}^{*}\right)-1 & \text { if } \epsilon_{f h, k}>\epsilon_{h f}+\epsilon_{f h}\end{cases}
$$

where $1+\bar{t}^{*} \equiv \sum_{k}\left(1+\hat{t}_{k}^{*}\right) \frac{X_{f h, k}}{X_{f h}}$ is the trade-weighted average NRTB. The above characterization indicates that in a one-sector model the optimal nonrevenue tariff is always zero-i.e., $\epsilon_{f h, k}=\epsilon_{h f}<\epsilon_{h f}+\epsilon_{f h}$. Allowing for tariffs to vary by sector, however, the optimal NRTB would be positive if sector $k$ is sufficiently small and features a sufficiently large trade elasticity, $\theta_{k}{ }^{19}$ In Section 6, we calibrate our model to actual sectoral trade data and find that four sectors in the US economy display such properties: Wheat, Rice, Diary, and Apparel. Hence, the optimal US tariff on Wheat is non-zero even without tariff revenue considerations. Intuitively, restricting imports in a relatively small, but high-elasticity sector lowers the foreign labor wage and

\footnotetext{
${ }^{19}$ In theory, one can easily construct an example where sector $k$ is subject to a positive non-revenue tariff. One example corresponds to a $K$-sector economy where $\alpha$ 's are uniform, and Home and Foreign are symmetric. Hence, $X_{j i, k}=X_{j i} / K$ for all $k$, and for the non-revenue tariff to be positive we should have $\theta_{k}>2 \sum_{k^{\prime}=1}^{K} \frac{\theta_{k^{\prime}}}{K}$. That is, if sector $k$ has a trade elasticity double the simple average elasticity, the Home government will impose a positive tariff on that sector, even when tariff revenue bears no value to the government.
} 
the import price in all other sectors. In practice, these "cross-price" effects alone could be large enough to offset the welfare loss due to price increase in the taxed sector.

\section{Quantitative Analysis}

This section applies our theoretical results to international trade data. We calibrate our model to mach US and Chinese factual trade shares, trade elasticities and applied tariffs across 33 sectors. The data is sourced from the Global Trade Analysis Project database (GTAP 8) which provides industrylevel trade, production, and tariff data. Ossa (2014) eliminates trade imbalances from this data set, and estimates a sector-specific trade elasticity for each of the 33 sectors in the sample. Focusing on this data allows us to contrast the predictions of our supposedly long-run model to that of Ossa (2014), which features short-run profit shifting effects.

First, we consider Home to be the US and Foreign to be an aggregate of the rest of the world (ROW). For identification purposes, we impose three parametric restrictions on preferences the gravity parameters: $(i) U_{i}(\mathbf{Q})=$ $\Pi_{k=1}^{32} Q_{i, k}^{\alpha_{i, k}},(i i) N_{j, k} \chi_{j i, k}=N_{i, k} \chi_{j j, k}=T_{j, k}$, and (iii) $\tau_{j i, k}=\tau$ for all $i, j$, and $k$. The parameters necessary to compute the optimal tariff are, therefore, the sector-specific exporter fixed effects $T_{j, k}$, and the economy-wide transport cost parameter, $\tau$. We set exporter fixed effects, $T_{j, k}$, to match sectoral production shares. Similarly, given the applied tariffs we choose the transport cost parameter, $\tau$, to match trade shares. Given the calibrated parameters and the sector-specific trade elasticities, we compute the optimal US trade tax schedule using Propositions 1 and 2. To handle multiplicity we invoke a clause in the US constitution that prohibits export taxes-we peg the export subsidy on Animal Products to zero, which entails a positive optimal subsidy on all remaining sectors.

Without Propositions 1 and 2, computing the optimal trade tax vector involves the method of mathematical programming with equilibrium constraints (MPEC) developed by Su and Judd (2012) (see Ossa (2014) for an 
application). Compared to the standard MPEC method, our analytical characterization of the optimal trade tax reduces computation time considerably-applying Propositions 1 and 2 we can calculate the optimal tax vector 27-times faster.

The top panel in Figure 2 displays the unrestricted optimal trade tax schedule for the US, and compares it to applied tariffs across the 33 sectors in the sample. Sectors are sorted according to their trade elasticity $\theta_{k}$, with low- $\theta$ (more differentiated) sectors to left and high- $\theta$ (more homogeneous) sectors to the right. The optimal tax schedule for the US consists of a uniform $111.7 \%$ tariff and a varying export subsidy averaging at $57.9 \%$. The optimal export subsidy varies with $(i)$ the trade elasticity, $\theta_{k}$, and (ii) the comparative advantage of the US, $T_{h, k} / T_{f, k}$. A simple variance decomposition implies that variations in $\theta_{k}$ account for $99.4 \%$ of the variation in the optimal US export subsidy. This outcome simply reflects that, factually, traded sectors are far from homogeneous-as implied by our theory the role of comparative advantage diminishes the more differentiated the traded sectors.

\subsection{Interdependence of Policies: The Effect of Incomplete Agreements}

In light of our theoretical results, we now study the effect of incomplete agreements that restrict only a subset of policies and leaves the rest to the discretion of the governments. To this end, we analyze how restricting a subset of policies affects the optimal level of unrestricted policies by conducting two counter-factual policy scenarios: (1) a negotiated ban on export subsidies and no restriction on tariffs; (2) a negotiated ban on export subsidies and tariff liberalization in a subset of sectors.

If export subsidies were prohibited, the optimal import tariff would be described by Proposition 1. The bottom panel of Figure 2 illustrates the optimal tax schedule for the US when export subsidies are banned and set to zero. In that case, the optimal policy schedule consists of a uniform $67.6 \%$ 
Figure 2: U.S. optimal trade policy

Unrestricted Optimal Tax Schedule

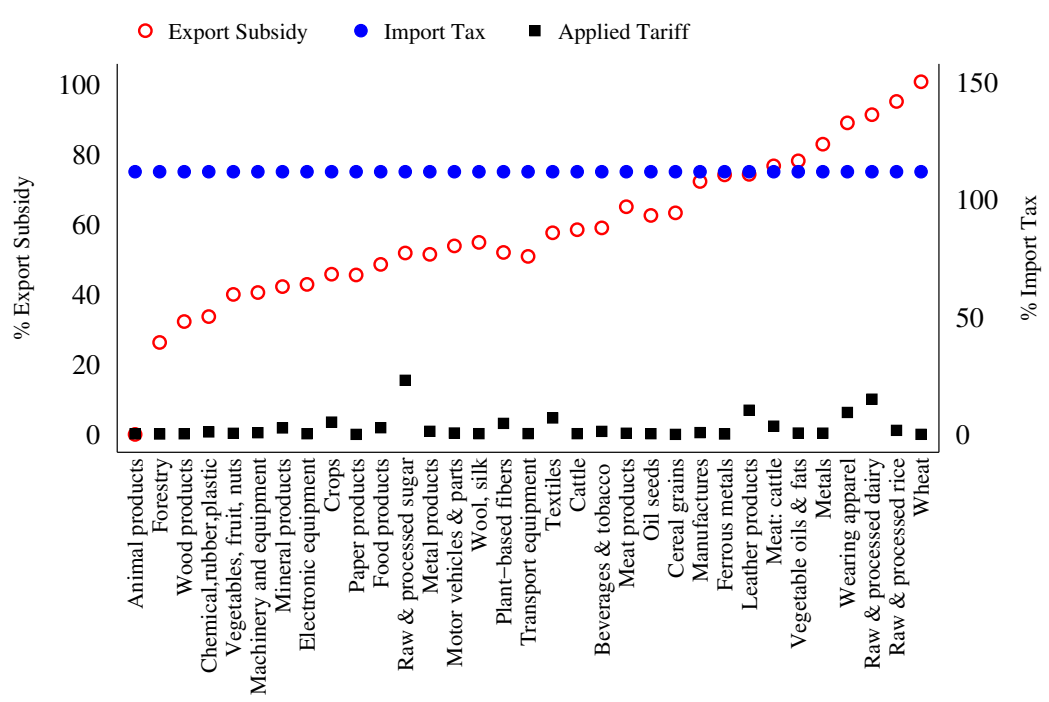

Optimal Tax Schedule when Export Policy is Restricted

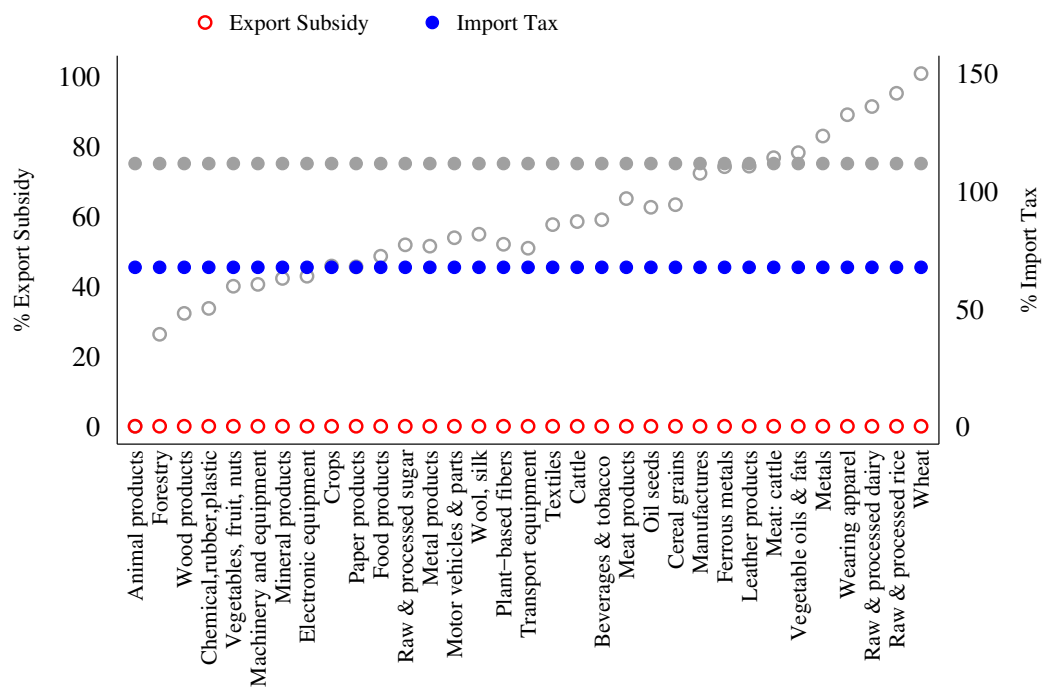

Note: Sectors are sorted based on their trade elasticity $\theta_{k}$ - the highest $\theta$ sectors are to the right. All optimal tax rates are computed given factual applied tariffs in the rest of the world. The uniform noncooperative U.S. tariff is $67.6 \%$. 
import tariff, which is $44 \%$ below the unrestricted uniform tariff. Considering our theory, this is not a trivial reduction in import tariffs. In fact, a ban on export subsidies has real effects, and reduces the overall level of protection substantially (we will compute these welfare effects in the following section). By contrast, in a model with only one import and one export good, a ban on export subsidy would have no impact on the overall level of protection.

In the second scenario, in addition to a ban on export subsidies, the governments negotiate zero tariffs in half of the sectors with the highest $\theta_{k}$. Under this scenario, we compute the vector of optimal US import tariffs in the remaining non-liberalized sectors. As shown by Proposition 3, due to complementarity between sectoral tariffs, negotiated liberalization in a subset of sectors leads to voluntary (i.e., unilateral) tariff cuts in non-liberalized sectors. These complementarity effects are displayed in Figure 3, where the optimal tariff on non-liberalized (low- $\theta_{k}$ ) sectors drops to about $43 \%$, down from $67.5 \%$. Alternatively, had partial liberalization happened in the low$\theta_{k}$ sectors, we would have observed an even greater unilateral tariff cut in non-liberalized sectors.

\subsection{Welfare Impact}

Using the calibrated model we conduct multiple counter-factual welfare analyses. First, we compute the welfare effects of a multilateral tariff liberalization between the US and ROW. To this end, we compare aggregate welfare in the factual equilibrium to that in a counter-factual equilibrium with zero applied tariffs. The results (reported in Table 1) indicate that tariff liberalization raises US welfare by only $0.68 \%$, and has a rather insignificant effect on the ROW. ${ }^{20}$ These numbers could be used as benchmarks to evaluate the effect of other policies. The second policy we consider involves a unilateral policy reform in which the US uniformizes sectoral tar-

\footnotetext{
${ }^{20}$ The ROW experiences a negligible loss from multilateral liberalization because it applies tariffs to the US that are 4.5-times larger than those applied by the US.
} 
Figure 3: Complementarity of import tariffs across sectors.

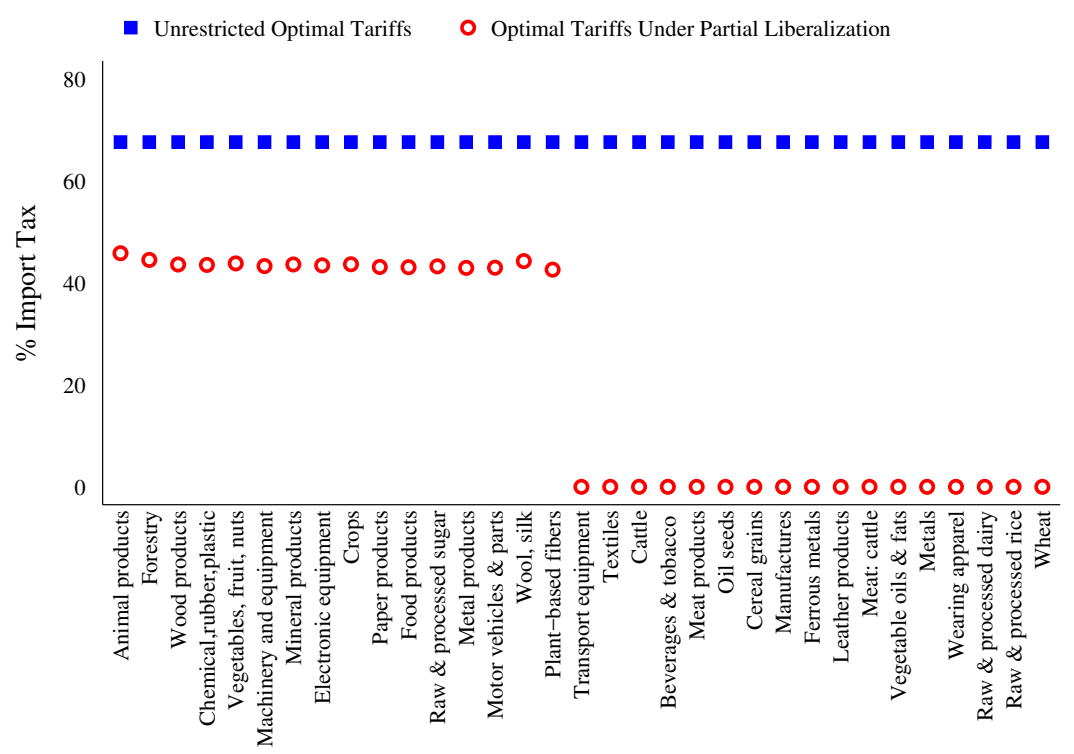

Note: Sectors are sorted based on their trade elasticity $\theta_{k}$ - the highest $\theta$ sectors are to the right. We restrict import tariffs to be zero in 16 sectors with the highest $\theta_{k}$ and compute the optimal import tariff in the renaming 17 sectors. 
iffs-i.e., all sector are subjected to a trade-weighted average applied tariff of $1.4 \%$. This reform will increase US welfare by $0.86 \%$, while making the ROW worse off by $0.13 \%$. Remarkably, the welfare-enhancing effects of the "uniform tariff" policy are greater than that of a full on multilateral tariff liberalization.

In a second set of counterfactual exercises, we compute the welfare effects of optimal unilateral policies. First, we compute the welfare effects that result from the imposition of unilaterally optimal US tariffs. Second, we compute the welfare effects that result from the imposition of unilaterally optimal US trade taxes, which involve both import tariffs and export subsidies. Our findings, which are reported in the last two rows of Table 1, can be summarized as follows. A unilaterally optimal import policy could raise the real per capita income of the US by $3.48 \%$. In comparison, a unilaterally optimal trade policy that involves export subsidies could raise the real per capita income of the US by $3.55 \%$. However, the application of optimal export subsidies -while more beneficial to the US- would impose a greater negative externality on the ROW. As seen in Table 2, similar effects arise when China imposes unilaterally optimal trade taxes on the ROW.

\section{Concluding Remarks}

We revisit the problem of optimal trade taxation in a general equilibrium model that features many differentiated sectors. Our analysis covers a large class of canonical trade models-including Costinot et al.'s (2011) multisector version of the Eaton-Kortum model, Chaney's (2008) version of the Melitz model, and Dornbusch et al.'s (1977) Ricardian trade model.

We find that under certain conditions the optimal trade tax schedule involves a uniform import tariff rate and a sector-specific export subsidy that increases with the sector-wide trade elasticity. We show that in competitive models, the main condition for the optimality of uniform tariffs is the constancy of the unit labor requirement within sectors. In monopolistically competitive models, in addition to the constancy of the unit labor 
Table 1: The Effect of U.S. trade Policy on National and Global Welfare

\begin{tabular}{lcc}
\hline & \multicolumn{2}{c}{$\%$ Change in Welfare Relative to Factual } \\
\cline { 2 - 3 } Counterfactual Scenario & U.S. & R.O.W. \\
\hline Multilateral Tariff Liberalization & $0.68 \%$ & $-0.01 \%$ \\
Uniformizing Applied Tariffs & $0.86 \%$ & $-0.13 \%$ \\
Optimal Unilateral Import Policy & $3.48 \%$ & $-1.18 \%$ \\
Optimal Unilateral Trade Policy & $3.55 \%$ & $-1.26 \%$ \\
\hline
\end{tabular}

Note: This table reports changes in welfare when moving to four counterfactual scenarios. Multilateral tariff liberalization is when both the US and Rest of World (ROW) eliminate their applied tariffs. Uniformizing applied tariffs corresponds to the case where the US unilaterally revises its trade policy by applying a uniform 1.4\% tariff across all sectors (which is equal to its trade-weighted average applied tariff). Optimal unilateral import policy corresponds to the case where the US imposes a unilaterally optimal tariff. Optimal unilateral import policy corresponds to the case where the US imposes an optimal trade tax that includes a uniform tariff a sector-specific export subsidies.

Table 2: The Effect of China's trade Policy on National and Global Welfare

\begin{tabular}{lcc}
\hline & \multicolumn{2}{c}{$\%$ Change in Welfare Relative to Factual } \\
\cline { 2 - 3 } Counterfactual Scenario & China & R.O.W. \\
\hline Multilateral Tariff Liberalization & $0.19 \%$ & $0.11 \%$ \\
Uniformizing Applied Tariffs & $1.05 \%$ & $-0.13 \%$ \\
Optimal Unilateral Import Policy & $2.26 \%$ & $-0.86 \%$ \\
Optimal Unilateral Trade Policy & $2.46 \%$ & $-0.98 \%$ \\
\hline
\end{tabular}

Note: This table reports changes in welfare when moving to counterfactual scenario. Multilateral tariff liberalization is when both China and the Rest of World (ROW) eliminate their applied tariffs. Uniformizing applied tariffs corresponds to the case where China unilaterally revises its trade policy by applying a uniform $10.7 \%$ tariff across all sectors (which is equal to its trade-weighted average applied tariff). Optimal unilateral import policy corresponds to the case where China imposes a unilaterally optimal tariff. Optimal unilateral import policy corresponds to the case where China imposes an optimal trade tax that includes a uniform tariff a sector-specific export subsidies. 
requirement, the optimality of uniform tariff requires conditions that preclude profit shifting and firm-delocation effects.

Our analysis reveals two novel trade policy interdependencies: i) Import tariffs are complementary across sectors and ii) Import policy is an imperfect substitute for export policy. The result that import policy is only an imperfect substitute for export policy has an important and novel implication about the design of trade agreements. At a broad level, this result implies that no trade liberalization may be achieved by restricting import policy alone. But importantly, an incomplete agreement that restricts only export policy and leaves import policy unconstrained will result in trade liberalization.

\section{References}

Alvarez, F. and R. E. Lucas (2007). General equilibrium analysis of the eaton-kortum model of international trade. Journal of monetary Economics 54(6), 1726-1768.

Anderson, J. E. and J. P. Neary (1992). Trade reform with quotas, partial rent retention, and tariffs. Econometrica: Journal of the Econometric Society, $57-76$.

Anderson, J. E. and J. P. Neary (2007). Welfare versus market access: the implications of tariff structure for tariff reform. Journal of International Economics 71(1), 187-205.

Bagwell, K. and S. H. Lee (2015). Trade policy under monopolistic competition with firm selection. Working Paper, Stanford University.

Baldwin, R. (2010). Unilateral tariff liberalisation. The International Economy 2010(14), 10-43.

Beshkar, M. and E. Bond (2016). Cap and Escape in Trade Agreements. Working Paper. 
Beshkar, M., E. Bond, and Y. Rho (2015). Tariff Binding and Overhang: Theory and Evidence. Journal of International Economics 97(1), 1-13.

Bickerdike, C. (1906). The Theory of Incipient Taxes. The Economic Journal 16(64), 529-535.

Bond, E. W. (1990). The optimal tariff structure in higher dimensions. International Economic Review, 103-116.

Bond, E. W., R. G. Riezman, and C. Syropoulos (2004). A strategic and welfare theoretic analysis of free trade areas. Journal of International Economics 64(1), 1-27.

Broda, C., N. Limão, and D. Weinstein (2008). Optimal tariffs and market power: the evidence. American Economic Review 98(5), 2032-2065.

Caliendo, L. and F. Parro (2014). Estimates of the trade and welfare effects of nafta. The Review of Economic Studies, rdu035.

Caron, J., T. Fally, and J. R. Markusen (2014). International trade puzzles: a solution linking production and preferences. The Quarterly Journal of Economics 129(3), 1501-1552.

Chaney, T. (2008). Distorted gravity: the intensive and extensive margins of international trade. The American Economic Review 98(4), 1707-1721.

Chor, D. (2010). Unpacking sources of comparative advantage: A quantitative approach. Journal of International Economics 82(2), 152-167.

Costinot, A., D. Donaldson, and I. Komunjer (2011). What goods do countries trade? a quantitative exploration of ricardo's ideas. The Review of economic studies, rdr033.

Costinot, A., D. Donaldson, J. Vogel, and I. Werning (2015). Comparative advantage and optimal trade policy. The Quarterly Journal of Economics 130(2), 659-702. 
Dornbusch, R., S. Fischer, and P. A. Samuelson (1977). Comparative advantage, trade, and payments in a ricardian model with a continuum of goods. The American Economic Review, 823-839.

Eaton, J. and S. Kortum (2002). Technology, geography, and trade. Econometrica 70(5), 1741-1779.

Fieler, A. C. (2011). Nonhomotheticity and bilateral trade: evidence and a quantitative explanation. Econometrica 79(4), 1069-1101.

Fukushima, T. (1979). Tariff structure, nontraded goods and theory of piecemeal policy recommendations. International Economic Review, 427-435.

Graaff, J. d. V. (1949). On optimum tariff structures. The Review of Economic Studies, 47-59.

Gros, D. (1987). A note on the optimal tariff, retaliation and the welfare loss from tariff wars in a framework with intra-industry trade. Journal of international Economics 23(3), 357-367.

Grossman, G. and E. Helpman (1995). Trade wars and trade talks. Journal of Political Economy 103(4), 675-708.

Hatta, T. (1977). A recommendation for a better tariff structure. Econometrica: Journal of the Econometric Society, 1859-1869.

Horwell, D. J. and I. F. Pearce (1970). A look at the structure of optimal tariff rates. International Economic Review 11(1), 147-161.

$\mathrm{Ju}, \mathrm{J}$. and K. Krishna (2000). Welfare and market access effects of piecemeal tariff reform. Journal of International Economics 51(2), 305-316.

Kahn, R. F. (1947). Tariffs and the terms of trade. The Review of Economic Studies 15(1), 14-19.

Krugman, P. (1980). Scale economies, product differentiation, and the pattern of trade. The American Economic Review 70(5), 950-959. 
Martin, W. and F. Ng (2004). A note on sources of tariff reductions in developing countries 1983-2003. World Bank 27.

Melitz, M. (2003). The impact of trade on aggregate industry productivity and intra-industry reallocations. Econometrica 71(6), 1695-1725.

Opp, M. M. (2010). Tariff wars in the ricardian model with a continuum of goods. Journal of International Economics 80(2), 212-225.

Ornelas, E. (2005). Trade creating free trade areas and the undermining of multilateralism. European Economic Review 49(7), 1717-1735.

Ossa, R. (2014). Trade wars and trade talks with data. The American Economic Review 104(12), 4104-4146.

Su, C.-L. and K. L. Judd (2012). Constrained optimization approaches to estimation of structural models. Econometrica 80(5), 2213-2230. 


\section{A Proof of Propositions 1}

We first characterize the optimal import tariff under zero export tax and show that it is uniform across sectors. We then show that the uniformity result continues to hold under an arbitrary set of export taxes/subsidies. In the interest of clarity, we prove the proposition for a two sector (i.e. four good) economy. All arguments, however, apply equally to an economy with an arbitrary number of sectors.

Optimal import tariff given zero export tax/subsidy. First, we write down the first order conditions (FOC), Then, we show that a unique vector of uniform tariffs satisfies the FOC. The FOC corresponding to sector $k$ can be written as:

$$
\frac{d V_{h}}{d t_{k}}=\frac{\partial V_{h}}{\partial Y_{h}} \frac{\partial Y_{h}}{\partial t_{k}}+\frac{\partial V_{h}}{\partial P_{h, k}} \frac{\partial P_{h, k}}{\partial t_{k}}+\left[\frac{\partial V_{h}}{\partial Y_{h}} \frac{\partial Y_{h}}{\partial \ln w}+\sum_{g} \frac{\partial V_{h}}{\partial P_{h, g}} \frac{\partial P_{h, g}}{\partial \ln w}\right] \frac{d \ln w}{d t_{k}}
$$

Given the balanced trade condition $\left(X_{f h}=X_{h f}\right)$ the wage effect of a tariff in sector $k$ is given by

$$
\frac{d \ln w}{d t_{k}}=\frac{\frac{\partial \ln X_{f h}}{\partial t_{k}}}{\frac{\partial \ln X_{h f}}{\partial \ln w}-\frac{\partial \ln X_{f h}}{\partial \ln w}}
$$

Additionally, note that $\frac{\partial \ln X_{h f}}{\partial \ln w}=1+\epsilon_{h f}$, where $\epsilon_{h f} \equiv \frac{\partial \ln \lambda_{h f}}{\partial \ln w}$. Roy's identity implies that $\frac{\partial V_{h}}{\partial P_{h, k}}=-\frac{Y_{h, k}}{P_{h, k}} \frac{\partial V_{h}}{\partial Y_{h}}$. Furthermore, $\frac{\partial \ln P_{h, k}}{\partial t_{k}}=\frac{\lambda_{f h, k}}{1+t_{k}}$ and $\frac{\partial \ln P_{h, k}}{\partial \ln w}=\lambda_{f h, k}$. Accounting for these relations, the FOC will become

$$
\frac{\partial V_{h}}{\partial Y_{h}}\left(X_{f h, k}+\tilde{t}_{k} X_{h f} \frac{\partial \ln X_{f h}}{\partial t_{k}}\right)-\underbrace{\frac{Y_{h, k}}{P_{h, k}} \frac{\partial V_{h}}{\partial Y_{h}} P_{h, k} \frac{\lambda_{f h, k}}{1+t_{k}}}_{X_{f h, k} \frac{\partial V_{h}}{\partial Y_{h}}}+\left[\frac{\partial V_{h}}{\partial Y_{h}} \frac{\partial Y_{h}}{\partial w}+\sum_{g} \frac{\partial V_{h}}{\partial P_{h, g}} \frac{\partial P_{h, g}}{\partial w}\right] \frac{d w}{d t}=0
$$

where $\tilde{t}_{k} \equiv \frac{\sum_{g} t_{g} \frac{X_{f h, g}}{X_{f h}} \frac{\partial \ln X_{f h, g}}{\partial t_{k}}}{\sum_{g} \frac{X_{f h, g}}{X_{f h}} \frac{\partial \ln X_{f h, g}}{\partial t_{k}}}$ note that if $\frac{\partial \ln X_{f h, g}}{\partial t_{k}} \approx 0$ when $t \neq g$, then $\tilde{t}_{k} \approx t_{k}$. The FOC, therefore, can be further simplified as

$$
\begin{aligned}
\frac{\partial V_{h}}{\partial Y_{h}} & \left\{\tilde{R}_{f h}^{k} \frac{\partial \ln X_{f h}}{\partial t_{k}}+\left[Y_{h} \frac{\partial \ln Y_{h}}{\partial \ln w}-\sum_{g} Y_{h, g} \frac{\partial \ln P_{h, g}}{\partial \ln w}\right] \frac{d \ln w}{d t}\right\} \\
= & \frac{\partial V_{h}}{\partial Y_{h}}\left\{\tilde{R}_{f h}^{k} \frac{\partial \ln X_{f h}}{\partial t_{k}}+\left[R_{f h} \frac{\partial \ln R_{f h}}{\partial \ln w}-\lambda_{f h} Y_{h}\right] \frac{d \ln w}{d t}\right\}=0,
\end{aligned}
$$


where the above equation follows from the fact that $\sum_{g} Y_{h, g} \frac{\partial \ln P_{h, g}}{\partial \ln w}=\sum_{g} \lambda_{f h, g} Y_{h, g}=\lambda_{f h} Y_{h}$, and $R_{f h} \equiv \sum_{k} t_{k} X_{f h, k}$ and $\tilde{R}_{f h}^{k} \equiv \tilde{t}_{k} X_{f h}$. The term in the braces can further simplified as

$$
\begin{aligned}
& \tilde{R}_{f h}^{k} \frac{\partial \ln X_{f h}}{\partial t_{k}}+\left[\frac{\partial \ln R_{f h}}{\partial \ln w}-\lambda_{f h} Y_{h}\right] \frac{d \ln w}{d t} \\
= & \left\{\left[\left(1+\epsilon_{h f}\right) \tilde{R}_{f h}^{k}-\lambda_{f h} Y_{h}\right]+\left[R_{f h} \frac{\partial \ln R_{f h}}{\partial \ln w}-\tilde{R}_{f h}^{k} \frac{\partial \ln X_{f h}}{\partial \ln w}\right]\right\} \frac{d \ln w}{d t} .
\end{aligned}
$$

Therefore, altogether, the FOC becomes

$$
\frac{d \ln V_{h}}{d t_{k}}=\left\{\left[\left(1+\epsilon_{h f}\right) \tilde{R}_{f h}^{k}-\lambda_{f h} Y_{h}\right]+\left[R_{f h} \frac{\partial \ln R_{f h}}{\partial \ln w}-\tilde{R}_{f h}^{k} \frac{\partial \ln X_{f h}}{\partial \ln w}\right]\right\} \frac{\partial V_{h}}{\partial Y_{h}} \cdot \frac{d \ln w}{d t_{k}}=0 .
$$

Note that $\frac{d \ln w}{d t_{k}}<0$ and $\frac{\partial V_{h}}{\partial Y_{h}}>0$, the FOC implies that

$$
\begin{aligned}
\frac{d \ln V_{h}}{d t_{k}}=0 & \Longleftrightarrow \Gamma_{k} \equiv\left(1+\epsilon_{h f}\right) \tilde{R}_{f h}^{k}-\lambda_{f h} Y_{h}+R_{f h} \frac{\partial \ln R_{f h}}{\partial \ln w}-\tilde{R}_{f h}^{k} \frac{\partial \ln X_{f h}}{\partial \ln w}=0 \\
& \Longrightarrow \tilde{t}_{k}=\frac{\lambda_{f h} Y_{h}-R \frac{\partial \ln R_{f h}}{\partial \ln w}}{X_{f h}\left(1+\epsilon_{h f}-\frac{\partial \ln X_{f h}}{\partial \ln w}\right)} \forall k .
\end{aligned}
$$

Provided that all variables on the right hand side are aggregate variables, the above equation entails that $\tilde{t}_{1}^{*}=\ldots=\tilde{t}_{K}^{*}$. Uniformity of the actual tariffs then simply follows from contradiction. Specifically, suppose $t_{K}^{*}=\max \left\{t_{k}^{*}\right\}$ and $t_{1}^{*}=\min \left\{t_{k}^{*}\right\}$; if $t_{K}^{*} \neq t_{1}^{*}$ then $\tilde{t}_{K}^{*}>\tilde{t}_{1}^{*}$, which constitutes a contradiction. ${ }^{21}$ Uniformity, in turn, implies that $(i) \tilde{t}_{k}^{*}=t_{k}^{*}=\bar{t}^{*}$ for all $k$, (ii) $\tilde{R}_{f h}^{k}=R_{f h}=\bar{t}^{*} X_{f h}$, (iii) $R_{f h} \frac{\partial \ln R_{f h}}{\partial \ln w}=\tilde{R}_{f h}^{k} \frac{\partial \ln X_{f h}}{\partial \ln w}$, and (vi) $\lambda_{f h} Y_{h}=\left(1+\bar{t}^{*}\right) X_{f h}$. Plugging these relations into the FOC $\left(\Gamma_{k}=0\right)$ leads to the following specification for the uniform optimal tariff:

$$
\bar{t}^{*}=\frac{1}{\epsilon_{h f}}
$$

where $\epsilon_{h f} \equiv \frac{\partial \ln \lambda_{h f}}{\partial \ln w}$. Given that $\lambda_{h f} L_{f}$ is Foreign's aggregate export supply curve, $\epsilon_{h f}$ denotes the elasticity of Foreign's aggregate export supply curve. Q.E.D.

Optimal import tariff for an arbitrary set of export policies Note that $Y_{h}=L_{h}+R_{f h}+$ $R_{h f}^{x}$, where $R_{f h}\left(w ; 1+t_{1}, \ldots, 1+t_{K}\right) \equiv \sum_{g=1}^{K} t_{g} X_{f h, g}$ and $R_{h f}^{x}\left(w ; 1+x_{1}, \ldots, 1+x_{K}\right) \equiv \sum_{k=1}^{K} \frac{x_{k}}{1+x_{k}} X_{h f, k}$ denote export and import tax revenue, respectively. Hence, the first order conditions

\footnotetext{
${ }^{21}$ The fact that $\tilde{t}_{K}^{*}>\tilde{t}_{1}^{*}$ follows from the fact that $\tilde{t}_{k}$ is a weighted average tariff with the majority of weight assigned to sector $k^{\prime}$ s tariff-i.e., $\frac{\partial \ln X_{f h}}{\partial t_{k}} \Longrightarrow\left|\frac{X_{f h, g}}{X_{f h}} \frac{\partial \ln X_{f h, k}}{\partial t_{k}}\right|>\sum_{g \neq k} \frac{X_{f h, g}}{X_{f h}} \frac{\partial \ln X_{f h, g}}{\partial t_{k}}$.
} 
(FOC) under an arbitrary export tax

$$
\begin{aligned}
\frac{d \ln V_{h}}{d t_{k}}= & \frac{\partial V_{h}}{\partial Y_{h}} \frac{d Y_{h}}{d t_{k}}-\sum_{g} \frac{\partial V_{h}}{\partial P_{h, g}} \frac{d P_{h, g}}{d t_{k}} \\
& =\left\{\frac{\partial R_{h f}^{x}}{\partial w} \frac{d w}{d t_{k}}+\frac{d}{d t_{k}}\left(L_{h}+R_{f h}\right)\right\} \frac{\partial V_{h}}{\partial Y_{h}}-\sum_{g} \frac{\partial V_{h}}{\partial P_{h, g}} \frac{d P_{h, g}}{d t_{k}}
\end{aligned}
$$

We can apply a uniform export subsidy $(1+a)$ and a countervailing uniform import tariff $(1+a)$ without altering equilibrium outcomes (this is due to the Lerner symmetry). In that case, at the optimum tariff $\left(t_{1}^{*}, \ldots, t_{K}^{*}\right)$, the FOC should still hold for any given $a$ :

$$
\left\{\frac{\partial R_{h f}^{x}\left(w ; \frac{1+x_{1}}{1+a}, \ldots, \frac{1+x_{K}}{1+a}\right)}{\partial w} \frac{d w}{d t_{k}}+\frac{d}{d t_{k}}\left(1+R_{f h}\left(w ; 1+\tilde{t}_{1}, \ldots, 1+\tilde{t}_{K}\right)\right)\right\} \frac{\partial V_{h}}{\partial Y_{h}}-\sum_{g} \frac{\partial V_{h}}{\partial P_{h, g}} \frac{d P_{h, g}}{d t_{k}}=0
$$

where $1+\tilde{t}_{k} \equiv\left(1+t_{k}\right)(1+a)$. Note that $\Gamma(a) \equiv \frac{\partial R_{h f}^{x}\left(w ; \frac{1+x_{1}}{1+a}, \ldots, \frac{1+x_{K}}{1+a}\right)}{\partial w}$ is continuous in $a$, $\Gamma(0)>0$ and $\Gamma\left(\max _{k}\left\{x_{k}\right\}\right)<0$. Therefore, following the intermediate value theorem, there exists an $\bar{a}$ such that the $\Gamma(\bar{a})=0$, which implies the following FOC.

$$
\frac{d}{d t_{k}}\left(1+R_{f h}\left(w ; 1+\tilde{t}_{1}, \ldots, 1+\tilde{t}_{K}\right)\right) \frac{\partial V_{h}}{\partial Y_{h}}-\sum_{g} \frac{\partial V_{h}}{\partial P_{h, g}} \frac{d P_{h, g}}{d t_{k}}=\left.0\right|_{t=\left(\tilde{t}_{1}^{*} \ldots, \tilde{t}_{K}^{*}\right)}=0
$$

From proposition 1 , if follows that $\left(1+t_{k}^{*}\right)(1+\bar{a})=1+\bar{t}^{*}=1+\frac{1}{\epsilon_{h f}}$. That is, the optimal import tariff should be uniform for any arbitrary schedule of export tax. Q.E.D.

\section{B Proof of Proposition 2}

From corollary 1 we know that the optimal import tax should be uniform irrespective of the export tax. Therefore, we first characterize the optimal export tax for a zero uniform tariff. Then, using Lerner's symmetry we characterize the optimal tax schedule up to any given uniform tariff. To this end, we proceed by first deriving $\frac{d \ln Y_{h}}{d x_{k}}$ and $\frac{d \ln P_{h}}{d x_{k}}$ :

$$
Y_{h}=L_{h}+\sum_{g} \frac{x_{g}}{1+x_{g}} X_{h f, g} .
$$

Defining $R_{h f}^{x} \equiv \sum_{k} \frac{x_{k}}{1+x_{k}} X_{h f, k}$, we will have: 


$$
\frac{d V_{h}}{d x_{k}}=\frac{\partial V_{h}}{\partial Y_{h}} \frac{\partial Y_{h}}{\partial x_{k}}+\left[\frac{\partial V_{h}}{\partial Y_{h}} \frac{\partial Y_{h}}{\partial \ln w}+\sum_{g} \frac{\partial V_{h}}{\partial P_{h, g}} \frac{\partial P_{h, g}}{\partial \ln w}\right] \frac{d \ln w}{d x_{k}}
$$

where

$$
\frac{\partial Y_{h}}{\partial x_{k}}=\frac{X_{h f, k}}{\left(1+x_{k}\right)^{2}}+\frac{x_{k}}{1+x_{k}} X_{h f, k} \frac{\partial \ln X_{h f, k}}{\partial x_{k}}
$$

Also, given Roy's identity $\left(\frac{\partial V_{h}}{\partial P_{h, g}}=-\frac{Y_{h, g}}{P_{h, g}} \frac{\partial P_{h, g}}{\partial \ln w}\right)$ and that $\frac{\partial \ln P_{h, g}}{\partial \ln w}=\lambda_{f h, g}$, the term in the bracket can be simplified as

$$
\begin{aligned}
\frac{\partial V_{h}}{\partial Y_{h}} \frac{\partial Y_{h}}{\partial \ln w}+\frac{\partial V_{h}}{\partial P_{h, k}} \frac{\partial P_{h, k}}{\partial \ln w} & =\frac{\partial V_{h}}{\partial Y_{h}} \frac{\partial Y_{h}}{\partial \ln w}-\frac{\partial V_{h}}{\partial Y_{h}} \sum_{g} \frac{Y_{h, g}}{P_{h, g}} \frac{\partial P_{h, g}}{\partial \ln w} \\
& =\frac{\partial V_{h}}{\partial Y_{h}}\left\{R_{h f}^{x} \frac{\partial \ln R_{h f}^{x}}{\partial \ln w}-X_{f h}\right\} .
\end{aligned}
$$

Given that $\frac{\partial \ln X_{h f, k}}{\partial x_{k}}=-\epsilon_{h f, k} /\left(1+x_{k}\right)$ and $R_{h f}^{x} \frac{\partial \ln R_{h f}^{x}}{\partial \ln w}=X_{h f} \sum \frac{x_{g}}{1+x_{g}}\left(1+\epsilon_{h f, g}\right) \frac{X_{h f, g}}{X_{h f}}$, we can write $\frac{d V_{h}}{d x_{k}}$ as

$$
\frac{d V_{h}}{d x_{k}}=\frac{\partial V_{h}}{\partial Y_{h}}\left\{\frac{1}{\left(1+x_{k}\right)^{2}} \frac{X_{h f, k}}{X_{h f}}\left[1-x_{k} \epsilon_{h f, k}\right]+\left\{-1+\sum_{g} \frac{x_{g}}{1+x_{g}}\left(1+\epsilon_{h f, g}\right) \frac{X_{h f, g}}{X_{h f}}\right\} \frac{d \ln w}{d x_{k}}\right\}
$$

Hence, given that $\frac{\partial V_{h}}{\partial Y_{h}}>0$, the above equation implies the following FOC for the sector $k$ :

$$
\frac{1}{1+x_{k}} \frac{X_{h f, k}}{X_{h f}}\left[1-x_{k} \epsilon_{h f, k}\right]+\left\{\sum_{g} \frac{1}{1+x_{g}} \frac{X_{h f, g}}{X_{h f}}\left(x_{g} \epsilon_{h f, g}-1\right)\right\} \frac{d \ln w}{d \ln x_{k}}=0
$$

To establish that the FOC have a unique solution, note that for sector $k$ the above condition implies that:

$$
\frac{d \ln w}{d \ln x_{k}}=\frac{\frac{1}{1+x_{k}} \frac{X_{h f, k}}{X_{h f}}\left[1-x_{k} \epsilon_{h f, k}\right]}{\sum_{g} \frac{1}{1+x_{g}} \frac{X_{h f, g}}{X_{h f}}\left[1-x_{g} \epsilon_{h f, g}\right]} .
$$

Therefore,

$$
\frac{\frac{d \ln w}{d \ln x_{k}}}{\frac{d \ln w}{d \ln x_{g}}}=\frac{\frac{X_{h f, k}}{X_{h f}} \epsilon_{h f, k}}{\frac{X_{h f, g}}{X_{h f}} \epsilon_{h f, g}}=\frac{\frac{1}{1+x_{k}} \frac{X_{h f, k}}{X_{h f}}\left[1-x_{k} \epsilon_{h f, k}\right]}{\frac{1}{1+x_{g}} \frac{X_{h f, g}}{X_{h f}}\left[1-x_{g} \epsilon_{h f, g}\right]} \Longrightarrow x_{k} \epsilon_{h f, k}=x_{g} \epsilon_{h f, g} \equiv \omega .
$$


Inserting the above condition in the FOC implies:

$$
(1-\omega)\left\{\frac{1}{1+x_{k}} \frac{X_{h f, k}}{X_{h f}}-\left\{\sum_{g} \frac{1}{1+x_{g}} \frac{X_{h f, g}}{X_{h f}}\right\} \frac{d \ln w}{d \ln x_{k}}\right\}=0,
$$

which given that $0<\frac{d \ln w}{d \ln x_{k}}<1$ implies that $\omega=1$ is the unique solution to the FOC. ${ }^{22}$ That is, $x_{k}^{*}=1 / \epsilon_{h f, k}^{*}$ for all $k$. Given the Lerner symmetry, for a given uniform tariff $t^{*}$ the optimal tax schedule is thus uniquely given by

$$
\left(1+\bar{t}^{*}\right)\left(1+x_{k}^{*}\right)=\frac{1}{\epsilon_{h f, k}^{*}} .
$$

Q.E.D.

\section{Non-Revenue Tariffs}

Suppose the government disposes of tariff revenues rather than distributing them back to consumers. Noting that $Y_{h} \equiv L_{h}$, the first order conditions (FOC) facing the Home government will be

$$
\frac{d V_{h}}{d t_{k}}=\sum \frac{\partial V_{h}}{\partial P_{h, g}} \frac{d \ln P_{h, g}}{\partial t_{k}}=\frac{\partial V_{h}}{\partial Y_{h}}\left(Y_{h, k} \frac{\partial \ln P_{h, k}}{\partial t_{k}}+\sum_{g} Y_{h, k} \frac{\partial \ln P_{h, g}}{\partial \ln w} \frac{d \ln w}{d t_{k}}\right)=0 .
$$

Noting that $Y_{h, k} \frac{\partial \ln P_{h, g}}{\partial \ln w}=\left(1+t_{g}\right) X_{f h, g}, Y_{h, k} \frac{\partial \ln P_{h, k}}{\partial t_{k}}=X_{f h, k}$, and $\frac{\partial V_{h}}{\partial Y_{h}}>0$, the FOC becomes

$$
X_{f h, k}+\frac{d \ln w}{d t_{k}} \sum_{g}\left(1+t_{g}\right) X_{f h, g}=0
$$

The balanced trade condition entails that $\frac{d \ln w}{d t_{k}}=\frac{\frac{\partial \ln X_{h f}}{\partial t_{k}}}{\frac{d \ln x_{h f}}{d \ln w}-\frac{\partial \ln X_{f h}}{\partial \ln w}}$. Plugging $d \ln w / d t_{k}$ into the FOC we will get

$$
X_{f h, k}+\frac{(1+\bar{t}) X_{f h} \frac{\partial \ln X_{f h}}{\partial t_{k}}}{\frac{d \ln X_{h f}}{d \ln w}-\frac{\partial \ln X_{f h}}{\partial \ln w}}=0
$$

${ }^{22}$ Otherwise, if $\frac{1}{1+x_{k}} \frac{X_{h f, k}}{X_{h f}}-\left\{\sum_{g} \frac{1}{1+x_{g}} \frac{X_{h f, g}}{X_{h f}}\right\} \frac{d \ln w}{d \ln x_{k}}=0, \forall k$ then we would have $\frac{d \ln w}{d \ln x_{k}}=1$. 
where $1+\bar{t}=\sum\left(1+t_{k}\right) \frac{X_{f h, k}}{X_{f h}}$ is the trade-weighted average tariff. Noting that $\frac{\partial \ln X_{f h}}{\partial t_{k}}=$ $\sum_{g} \frac{\partial \ln X_{f h, g}}{\partial t_{k}} \frac{X_{f h, g}}{X_{f h}}$, and $\frac{\partial \ln X_{f h, k}}{\partial t_{k}}=\frac{-1}{t_{k}+1}\left[1+\theta_{k} X_{h h, k}\right]$ plus $\frac{d \ln X_{h f}}{d \ln w}=1+\epsilon_{h f}$ we will have

$$
X_{f h, k}-X_{f h, k} \frac{1+\bar{t}}{1+t_{k}} \frac{\left[1+\epsilon_{f h, k}\right]}{1+\epsilon_{h f}+\epsilon_{f h}}=0,
$$

where $\epsilon_{j i, k} \equiv\left|\frac{\partial \ln \lambda_{j i, k}}{\partial \ln w}\right|=\theta_{k} X_{h h, k}$ and $\epsilon_{j i} \equiv\left|\frac{\partial \ln \lambda_{j i}}{\partial \ln w}\right|=\sum_{k} \epsilon_{j i, k} \cdot \frac{X_{f h, k}}{X_{f h}}$, with $\sum_{k} \frac{X_{j i, k}}{X_{j i}}=1$ by construction. The FOC will hence reduce to

$$
\frac{t_{k}^{*}+1}{\bar{t}^{*}+1}=\frac{1+\epsilon_{f h, k}}{1+\epsilon_{f h}+\epsilon_{f h}}
$$

where $1+\bar{t}^{*}=\sum\left(1+t_{k}^{*}\right) \frac{X_{f h, k}}{X_{f h}}$. Provided that there always exists a $k$ such $\epsilon_{f h, k} \leq \epsilon_{f h}$, the above FOC rules out the possibility of an uniform optimal no-revenue tariff-i.e. $t_{k}^{*}=\bar{t}^{*}$. At $t_{k}=0, \forall k$ the optimality of a non-zero (positive) tariff on sector $k$ will require that $1<\frac{1+\epsilon_{f h, k}}{1+\epsilon_{h f}+\epsilon_{f h}}$, which amounts to $\epsilon_{f h, k}>\epsilon_{h f}+\epsilon_{f h}$. Descriptively, this condition requires the elasticity of Home's demand for foreign exports in sector $k$ be greater than the sum of Home and Foreign's aggregate import demand elasticity.

\section{Optimal Taxes in the Limiting Case $\left(\theta_{k} \rightarrow \infty\right)$}

Given our proof of uniqueness, we simply proceed to show that the solution to our optimal export tax equation satisfies the following when $\theta_{k}$ is sufficiently large:

$$
x_{k}^{*}+1=\frac{T_{h, k}}{T_{f, k}} \tau_{h f, k} w\left[1-\frac{\ln \left(\frac{T_{h, k}}{T_{f, k}} \tau_{h f, k} w-1\right) \theta_{k}}{\theta_{k}}\right],
$$

where $\tilde{T}$ denotes actual productivity rather than a distribution parameter. ${ }^{23}$ First, note that as $\theta_{k} \rightarrow \infty$ the tax rate implied by the above equation converge to the limit-pricing rate:

$$
\lim _{\theta_{k} \rightarrow \infty} x_{k}^{*}=\frac{\tilde{T}_{h, k}}{\tilde{T}_{f, k}} w .
$$

${ }^{23}$ Specifically, trade shares in absence of trade costs are given by:

$$
\lambda_{f h, k}=\frac{\left(w / \widetilde{T}_{f, k}\right)^{-\theta_{k}}}{\left(1 / \widetilde{T}_{h, k}\right)^{-\theta_{k}}+\left(w / \widetilde{T}_{f, k}\right)^{-\theta_{k}}}
$$


Now, we show that $x_{k}^{*}+1=\frac{T_{h, k}}{T_{f, k}} \tau_{h f, k} w\left[1-\frac{1}{\theta_{k}} \ln \left(\frac{T_{h, k}}{T_{f, k}} \tau_{h f, k} w-1\right) \theta_{k}\right]$ is a solution to our optimal tax-rate formula $\left(x_{k}^{*}=\frac{1}{\theta_{k} \lambda_{f f, k}}\right)$ as $\theta_{k}$ becomes sufficiently large. To this end, notice that trade shares in sector/good $k$ are given by

$$
\lambda_{f f, k}=\frac{\left(w / T_{f, k}\right)^{-\theta_{k}}}{\left(w / T_{f, k}\right)^{-\theta_{k}}+\left(\left[1+x_{k}\right] \tau_{h f, k} / T_{h, k}\right)}=\frac{\left(\frac{\left(1+x_{k}\right) \tau_{h f, k} T_{f, k}}{w T_{h, k}}\right)^{\theta_{k}}}{1+\left(\frac{\left(1+x_{k}\right) \tau_{h f, k} T_{f, k}}{w T_{h, k}}\right)^{\theta_{k}}} .
$$

Plugging the above equation into the optimal tax equation implies

$$
\begin{aligned}
\lim _{\theta_{k} \rightarrow \infty} \frac{1}{\theta_{k} \lambda_{f f, k}} & =\lim _{\theta_{k} \rightarrow \infty} \frac{1}{\theta_{k}\left(\frac{\left(1+x_{k}\right) T_{f, k}}{w T_{h, k}}\right)^{\theta_{k}}} \\
& =\frac{1}{\lim _{\theta_{k} \rightarrow \infty} \theta_{k}\left[1-\frac{\ln \left(\frac{\tilde{T}_{h, k}}{T_{f, k}} \tau_{h f, k} w-1\right) \theta_{k}}{\theta_{k}}\right]^{\theta_{k}}}=\frac{1}{1 /\left(\frac{\tilde{T}_{h, k}}{\tilde{T}_{f, k}} \tau_{h f, k} w-1\right)}=\lim _{\theta_{k} \rightarrow \infty} x_{k}^{*}
\end{aligned}
$$

which establishes that for sufficiently large $\theta_{k}$ 's, the unique solution to our optimal tax formula takes the following form, which reflects limit-pricingt

$$
x_{k}^{*}=\frac{\tilde{T}_{h, k}}{\tilde{T}_{f, k}} \tau_{h f, k} w\left[1-\frac{\ln \left(\frac{\tilde{T}_{h, k}}{\tilde{T}_{f, k}} \tau_{h f, k} w-1\right) \theta_{k}}{\theta_{k}}\right] .
$$

\section{E Proof of Proposition 4}

Let $R$ denote the set of liberalized sectors-i.e., $t_{k}=0$ if $k \in R$. Building on the the proof of Proposition 1, we first write the FOC condition for the unrestricted sectors. For an unrestricted sector $k$ the FOC implies that $\tilde{t}_{k}^{*}=\bar{t}^{*}=\frac{\lambda_{f h} Y_{h}-R_{f h} \frac{\partial \ln R_{f h}}{\partial \ln w}}{X_{f h}\left(1+\epsilon_{h f}-\frac{\ln X_{f h}}{\partial \ln w}\right)}$. Given that $\tilde{t}_{k}^{*}$ are uniform the unique solution to the FOC should consists of uniform vector of actual tariffs in the unrestricted sectors: $t_{k}^{*}=\tilde{t}_{k}^{*}=\bar{t}^{*}$ for all $k \notin R$. To determine $\bar{t}^{*}$ we simply need to solve the following:

$$
\bar{t}^{*}=\frac{\lambda_{f h} Y_{h}-R_{f h} \frac{\partial \ln R_{f h}}{\partial \ln w}}{X_{f h}\left(1+\epsilon_{h f}-\frac{\partial \ln X_{f h}}{\partial \ln w}\right)},
$$


where given the uniformity of the actual tariffs in the unrestricted sectors we have $(i)$ $\lambda_{f h} Y_{h}=X_{f h}+\bar{t}^{*} \sum_{k \notin R} X_{f h, k}$, and (ii) $R_{f h} \frac{\partial \ln R_{f h}}{\partial \ln w}=\bar{t}^{*} \sum_{k \notin R} \frac{\partial X_{f h, k}}{\partial w}$. Plugging the former relations in the above equation leads to the following formula for the optimal tariff in unrestricted sectors:

$$
t_{k}^{*}=\bar{t}^{*}=\frac{1}{\epsilon_{h f}+\sum_{g \in R} \frac{X_{h f, g}}{X_{h f}}\left(1-\frac{\partial \ln X_{f h, g}}{\partial \ln w}\right)}, \quad \forall k \notin R,
$$

where given that $\frac{\partial \ln X_{f h, g}}{\partial \ln w}<0$ the above equation implies that $\bar{t}^{*}<1 / \epsilon_{h f}$, where $1 / \epsilon_{h f}$ is the optimal tariff when no sectors are externally liberalized. Relatedly, using thee firstorder approximation that $\frac{\partial X_{f h}}{\partial t_{k}} \approx \frac{\partial X_{f h, k}}{\partial t_{k}}$ (note that as $\frac{X_{f h, k}}{X_{f h}} \rightarrow 0$ then $\frac{\partial X_{f h}}{\partial t_{k}} \rightarrow \frac{\partial X_{f h, k}}{\partial t_{k}}$ ) we can write the optimal tariff response in sector $k$ as a function applied tariffs in other sectors. In particular, the FOC for sector $k$ can be written as

$$
\Gamma_{k}=\left(1+\epsilon_{h f}\right) t_{k} X_{f h}-\lambda_{f h} Y_{h}+R_{f h} \frac{\partial \ln R_{f h}}{\partial \ln w}-t_{k} X_{f h} \frac{\partial \ln X_{f h}}{\partial \ln w}=0 .
$$

Note that

$$
\begin{gathered}
\left(1+\epsilon_{h f}\right) t_{k} X_{f h}-Y_{h} \lambda_{f h}=\left(1+\epsilon_{h f}\right) \sum t_{k} X_{f h, g}-\sum\left(1+t_{g}\right) X_{f h, g} \\
=\left(t_{k} \epsilon_{f h}-1\right) X_{f h}+\sum_{g}\left(t_{k}-t_{g}\right) X_{f h, g} .
\end{gathered}
$$

Similarly,

$$
R_{f h} \frac{\partial \ln R_{f h}}{\partial \ln w}-\tilde{R}_{f h}^{k} \frac{\partial \ln X_{f h}}{\partial \ln w}=-\sum_{g}\left(t_{k}-t_{g}\right) X_{f h, g} \frac{\partial \ln X_{f h, g}}{\partial \ln w} .
$$

Plugging in the above relations, the FOC becomes

$$
\Gamma_{k} \equiv\left(t_{k} \epsilon_{h f}-1\right) X_{f h}+\sum_{g}\left(t_{k}-t_{g}\right) X_{f h, g}\left[1-\frac{\partial \ln X_{f h, g}}{\partial \ln w}\right]=0 .
$$

Based on the above FOC, therefore, sector $k^{\prime}$ s best tariff response will be given by:

$$
t_{k}^{*}\left(t_{1}, \ldots, t_{K}\right)=\frac{1+\sum_{g \neq k} t_{g} \frac{X_{f h, g}}{X_{f h}}\left[1-\frac{\partial \ln X_{f h, g}}{\partial \ln w}\right]}{\epsilon_{h f}+\sum_{g \neq k} \frac{X_{f h, g}}{X_{f h}}\left[1-\frac{\partial \ln X_{f h, g}}{\partial \ln w}\right]},
$$

which indicates that the optimal tariffs in sector $k$ increase with the weighted average of tariffs applied in other sectors. 